NBER WORKING PAPER SERIES

MAJOR CHANGES IN CYCLICAL BEHAVIOR

Victor Zarnowitz

Geoffrey H. Moore

Working Paper No. 1395

NATIONAL BUREAU OF ECONOMIC RESEARCH

1050 Massachusetts Avenue

Cambridge, MA 02138

July 1984

The research reported here is part of the NBER's research program in Economic Fluctuations. Any opinions expressed are those of the authors and not those of the National Bureau of Economic Research. 
NBER Working Paper \#1395 Ju1y 1984

\section{Major Changes in Cyclical Behavior}

\section{$\underline{\text { ABSTRACT }}$}

Various structural, institutional, and policy changes have contributed to the evolution of business cycles. Since world war II business expansions have been much longer and contractions much shorter than before. Over nearly 200 years of U.S. history expansions have been long relative to contractions when prices had upward secular trends, and shorter when price trends were down. The rising price trend since the 1930's fits this pattern, although we find no association between the rate of inflation during each business cycle and the relative duration of the phases. Shifts in the industrial composition of employment, in labor-force participation, and in the distribution of personal income have all contributed to the post-1945 moderation of cyclical amplitudes. The variability of economic change was low by historical standards in both 1948-69 and 1969-81, although the inflation rate was much higher and real growth on the average lower after 1969. The recent long-term inflation is attributable mainly to the new persistence of upward price movements in business cycle contractions rather than to more rapid price increases during expansions. But prices have always been sensitive to the degree of severity of business contractions, and they still are. The same is true of short-term interest rates, although they became more sensitive during 1949-82 than before. Despite the deep changes in the economy, many basic characteristics of the business cycle remain unchanged, notably the timing relationships among groups of leading and lagging indicators.

Victor Zarnowitz Graduate School of Business University of Chicago 1101 East $58 \mathrm{th}$ Street Chicago, IL 60637

\author{
Geoffrey H. Moore \\ Graduate School of Business \\ Columbia University \\ 808 Uris Hall \\ New York, NY 10027
}


Contents

I. Business Cycles and Growth: Background and Some Hypotheses........2

II. Three Types of Change.................................4

III. Durations of Cyclical Phases Before and After world war II........6

IV. Business Cycle Phases and Long-Term Trends in Prices............8

v. The Reduced Severity of Recessions since world war II...........12

VI. Structural Shifts in Employment and Their Cyclical Effects........15

VII. Trends and Cyclical Changes in Unemployment

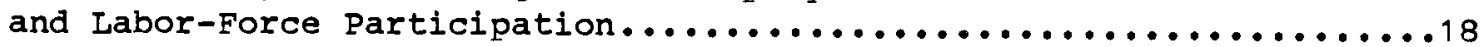

vIII. Changing Sources of Personal Income and the Business Cycle........23

IX. Growth Rates and Variability of Economic Change..............26

$x$. Changes in the Cyclical Behavior of Prices................... 28

XI. Changes in the Cyclical Behavior of Interest Rates..................

XII. Changes in the Timing of Leading and Lagging Indicators............. 37

xIII. Summary and Conclusions.............................40 


\section{MAJOR CHANGES IN CYCIICAL BEHAVIOR}

In the long stretch of time covered by business cycles, the economies of the industrialized world underwent many profound changes of structure, institutions, and modes of operation. Business cycles continued to have much in common as the most durable and pervasive form of short-term motion of these economies, but they also changed significantly. This study seeks to identify and analyze some of these changes. We concentrate on the longer and relatively well-established developments in the United States.

Sections I and II review some historical facts and hypotheses concerned with types of change in cyclical behavior. Next we take a long-run view of the durations of cyclical phases, note the shifts in the relative length of expansions and contractions (III), and relate them to changing trends in prices (IV). Section $V$ examines the amplitudes of cyclical movements in production and employment during the last hundred years. There follows an analysis of structural shifts in employment and their cyclical effects (VI); trends and cyclical changes in unemployment and labor-force participation (VII); and the consequences for the business cycles of the altered composition of personal income, reflecting the expansion of government, transfer payments, etc. (VIII). A discussion of the relationship between growth and variability of economic change (IX) completes this part of our report.

The remaining sections deal with changes in particular categories of cyclical indicators. Of particular interest here is the behavior of wholesale or producer prices $(X)$ and interest rates $(X I)$. Also, we examine the consistency of timing of the leading, coincident, and lagging indicators over as long a time period as the data allow (XII). Finally, we present our conclusions and suggestions for further research. 
I. Business Cycles and Growth: Background and Some Hypotheses

Business cycles defined as recurrent sequences of persistent and pervasive expansions and contractions in economic activities are at least as old as the modern industrialization and growth processes in the principal capitalist countries. The earliest evidence of their presence, from British and U. S. business annals and statistics, reach back into the eighteenth century.

The impressively high long-term growth rates of the era are well documented by the series of decade averages that reveal upward trends in employment, output, capital, productivity, and per capita consumption (see., e.g., Kuznets, 1971 ; U. S. Department of Commerce, 1973). However, over shorter periods, growth of the major private-enterprise economies was very uneven. Each decade witnessed at least one contraction of aggregate economic activity in each country, but more typically two and sometimes three. This refers to all countries covered by the business annals (Thorp, 1926) and the NBER business cycle chronologies (Burns and Mitchell, 1946).1 Most of these setbacks were mild but some were serious. A contraction was always followed by an expansion, which as a rule would consist of a recovery to the highest levels previously attained and a phase of net growth ending in a new record high ("peak") of activity. only on a few occasions did a peak fail to exceed the preceding peak. Similarly, successive troughs usually reached higher levels, except when a particularly weak recovery or deep depression occurred. Thus overall growth was achieved through expansionary spurts punctuated every few years by mild but generalized slowdowns or recessions and at longer irregular intervals by major depressions. During this epoch, the economies, societies, and political systems involved changed profoundly in many respects. There is substantial agreement among those who studied the subject intensively that business cycles are "a product of culture. - found only in modern nations where economic activities are 
organized mainly through business enterprises and where individuals enjoy considerable freedom in producing, pricing, trading, and saving or investing" (Burns, 1968, p. 228)..$^{2}$ It is therefore plausible to look for important changes in business cycles as a result of the changes in the structure of production, markets, institutions, and policies.

It is also possible to argue that the influence runs partly in the opposite direction and to see in the development of business cycles a major instrument for changes in the economy and society. Marx predicted a trend toward intensification of crises as capital-labor ratios increase, workers are displaced and pauperized, and profit rates fall, but his predictions were belied by the spread of prosperity and the capacity of capitalism and democracy first to survive and then to avoid severe depressions and bouts of high unemployment. Keynes worried about whether investment will absorb saving at full employment in countries growing in wealth, where capital accumulation lowers the return to investors. Hansen moved further, expecting weaker booms and deeper slumps to result from reduced opportunities for investment and increased propensity to save in "mature economies" with slower population growth. History dealt as harshly with these new "secular stagnation" hypotheses as it did with the earlier ones. ${ }^{3}$ Yet they are revived in various forms whenever sluggish business conditions prevail for some time, as in the recent period of so-called stagflation.

Conversely, in times of substantial stability and growth such as the mid$1920 \mathrm{~s}$ and $1960 \mathrm{~s}$ in the United States, the idea tends to gain ground that business cycles are becoming "obsolete" or are being "ironed out" by better public and business policies. In 1921-29, the Federal Reserve system "took--and perhaps even more was given--credit for the generally stable conditions that prevailed, and high hopes were placed in the potency of monetary policy as then administered" (Friedman and Schwartz, 1963, p. 240). In the mid-1960s, many 
economists helieved that the new use of discretionary fiscal policy was on its way to "dethroning the cyclical model" (Heller, 1966; see also R. A. Gordon, 1969, pp. 26-29) .

\section{Three Types of Change}

It is useful to distinguish three types of change in the cyclical behavior of the market-oriented economies:

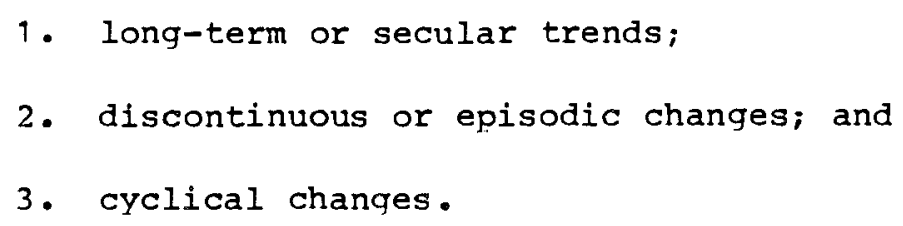

The hypotheses noted in section I envisage a gradual intensification or a gradual moderation of business cycles, and hence concern the first type. These are presumably irreversible changes or trends that can be projected.

The second type are temporary changes observed in particular periods. They may or may not continue and may or may not be reversed.

The third type refers to "cycles of cycles." Here the NBER-designated business cycles are viewed as subdivisions of longer major cycles or as mixtures of several distinct types. Four patterns, named for the economists who have investigated them in detail, are found in the literature:

1. The Kondratieff (about 48 to 60 years). These "long waves" have been associated with large movements in the level of prices and perhaps also with major technological innovations, but they do not show up in the volumes of production and consumption. Too few of such swings have been observed to prove or disprove their existence conci." ively.

2. The Kuznets ( 15 to 25 years). These cycles have been associated with construction of buildings and transport facilities (highways, rail lines, etc.), growth of population and labor force, urban 
development, and business formation. Here there is more supportive evidence of an historical nature.

3. The Juglar (about 7 to 10 years). These are the "major" business cycles, such as the Great Depression of the 1930's, that have received a great deal of attention in academic literature.

4. The Kitchin (about 3 to 4 years). These "minor" or "40-month" business cycles are often related to fluctuations in inventory investment.

Schumpeter (1939, vol. I, ch. V) developed the much-discussed scheme of three Kitchins per Juglar and six Juglars per Kondratieff. Burns and Mitchell (1946, ch. 11) reported largely negative or inconclusive results from tests of the former hypothesis for the United States. More generally, they found that long-run cyclical changes rarely had a dominant influence on the short-run cyclical behavior of a sample of U. S. series on general business activity, prices, production, investment in capital goods, and yields and the volume of trade in security markets.

Business cycles have certainly varied greatly in amplitude, diffusion, and duration, and important distinctions can be made between major and minor cycles, e.g., with respect to the relative roles and behavior of monetary aggregates, fixed investment, and inventory investment. But these matters will not occupy us here. There is little evidence of periodicities in the occurence of groups of major and minor cycles. However, we shall consider, in the light of presentIy available data, one old hypothesis related to the Kondratieff cycles, namely that business cycle expansions have tended to be 1 nger (and larger?) and contractions shorter (and smaller?) during the upward phases of the long waves in prices than during the downward phases. 
This paper, then, will focus in particular on the "secular" changes in cyclical behavior, a category that would naturally seem to deserve most attention. However, the secular and the discontinuous changes are not necessarily clearly differentiated. Not all trends can be safely projected and not all changes labeled secular may prove to be irreversible.

\section{Durations of Cyclical Phases Before and After world war II}

Studies of business cycles in the pre-World war II era have not been able to document major changes of either secular or discontinuous type. Tests by Burns and Mitchell (1946, ch. 10) gave little or no support to the view that substantial long-term changes occurred in the durations and amplitudes of cyclical movements in the sample of long U. S. time series. Mills' (1926) hypothesis that the cycles tend to get shorter in stages of rapid growth also failed to be confirmed by these tests. Comparisons of cycles before and after 1914 (then often alleged to have marked a "break" in American business history) indicated more basic similarities than differences, although the fluctuations during the period between the two world wars were unusually large.

Such major changes of systematic nature as can be observed in aggregate measures and particular aspects of cyclical behavior refer principally to comparisons between the period after world war II and the earlier era. As shown in Table 1, the eight contractions of 1945-82 were on the average much shorter, and the eight expansions much longer, than the corresponding phases in each of the three subsets with equal numbers of consecutive business cycles that together span the preceding century ( 1 ines $1-4$, columns 3 and 5). In 1846-1945, the mean duration of expansions was 30 months, that of contractions 20 months; in 1945-82, expansions averaged 45 months and contractions 11 months. 
The proportions of time that the economy spent declining dropped from $41 \%$ in 1846-1945 to $20 \%$ in $1945-82$ (column 9). These results are altered but little, to $45 \%$ and $25 \%$, respectively, when five cycles are omitted that include the long wartime expansions and the relatively short postwar contractions (column 10). The mean durations of the pre-1945 and post-1945 peacetime expansions are 26 and 34 months; contractions, 21 and 11 months.

A few of the mildest contractions in the NBER chronology of the 19th century cycles may have been actually episodes of below-trend but still positive growth rates, that is, pronounced retardations rather than absolute declines (Zarnowitz, 1981). That is, the chronology may have (inadvertently) recognized some growth cycle slowdowns rather than recessions, which would tend to make expansions and contractions more nearly equal in length (see Moore and zarnowitz, section VIII, in this volume). But allowing for this possibility would not significantly alter our conclusions. The proportions of time in contractions for peacetime cycles, recalculated on this assumption, would be $40 \%$ pre-1945 and (an unchanged) $25 \%$ post-1945.

Contractions became more uniform in length after world war II (column 6). Expansions became less uniform but this is chiefly the effect of the wars, all but one of which occurred in the last two of our four periods (column 4).

with regard to the total cycle durations, neither the means nor the standard deviations indicate any significant trends. Expansions lengthened and contractions shortened drastically but cycle lengths remained about the same (columns 7 and 8 ).

One of the implications of these findings is that contractions have become more predictable as to length than they were in earlier times. For example, if we take two standard deviations as the likely range, this was eight months in the period 1945-82. Added to the mean of 11 months, this makes 19 months the 
pracical upper limit. In fact, no contraction in this period lasted more than 17 months. Before 1945, the estimated ranges was 26 months, yielding an upper limit of 46 months, which was not exceeded even in the Great Depression ( 43 months ) .

IV. Business Cycle phases and Long-Term Trends in prices

Between 1789 and 1932, wholesale and consumer prices in the Uhited states have followed alternating upward and downward trends (Table 2). The long upswings lasted between 21 and 25 years, the long downswings varied more, from 12 to 32 years. These movements largely cancelled each other over the entire stretch of more than 140 years, so that the level of prices at the bottom of the Great Depression was not much higher than when George Washington took office. The half-century since 1932, however, witnessed the longest, largest, and most continuous inflation on record. Except in the recessions of 1937-38 and 1948-49, no significant price-level declines occurred in this period. wholesale prices increased by a factor of almost 9, consumer prices by a factor of 7 (cf. columns 4-7 of the table).

\section{Table 2}

Apart from the secular trends, the comprehensive frice indexes show generally procyclical short-term movements. Before 1932, they rose during most business expansions and fell during most business contractions, conforming in this sense about three quarters of the time.4 In periods of upward trend, the cyclical rises in prices were on the average large and the declines small; in periods of downward trend, the opposite situation prevailed, i.e., the rises tended to be small and the declines large (columns 8 and 9). But after 1949 prices kept increasing even wh:" the economy declined, although virtually every major slowdown and recession was associated with a temporary reduction in the inflation rate. 
To be sure, the long-period averages in Table 2 conceal a very large amount of variation over time, both between the wartime and peacetime episodes and among the latter. Nonetheless, it is important to note that over the last fifty years as a whole inflation became a grave problem not because it was unusually high during expansions but because, unlike in earlier times, it was only slowed, not reversed, during contractions. The booms have not grown more inflationary but the deflationary slumps have disappeared. Indeed, the average percentage increase per year in wholesale prices is 1.8 for the ten recessions of 1937-82, substantially higher than the 1.2 figure for the entire 193 year period covered in Table 2 .

In his introductory chapter to Thorp's Business Annals $(1926, p p .65-66)$, Mitchell observed that the ratios of "prosperous" to "depressed" years have been systematically higher in periods of rising trends in wholesale prices than in periods of declining trends. For the United states and England, the former ratios averaged 2.7 and 2.3 , the latter 0.8 and 0.6 , respectively. About twenty years later, armed with better and longer chronologies, Burns and Mitchell confirmed the hypothesis that long swings in prices were associated with the relative length of business cycle expansions and contractions (1946, pp. 437-438 and 538). The results based on their data for Great Britain, France, and Germany are presented in Table 3, sections B, C, and D. Section A shows more detailed findings for the United States, based on longer and updated records (see Moore, 1983, ch. 15).

\section{Table 3}

In each period of rising trend in prices, expansions last.e on the average much longer than contractions, in most instances more than twice as long. In each period of falling trend in prices, expansions tended to be either about as long as contractions (this is so for the United states) or considerably shorter 
than contractions (for the other countries). These contrasts are both regular and large (Table 3 , columns 2,5 , and 7 ).

As a result, the relative frequency of expansions has been greater in the long upswings of prices, that of contractions in the long downswings (cf. columns 1 and 4 ). Hence the total phase durations and their ratios add further emphasis to the showing of the corresponding statistics for the average phase durations (columns 3,6 , and 8 ).

Prices have risen strongly in wartime expansions, but the relationship documented above does not rely mainly on this fact. When the five major wars of $U$. S. history are excluded (as in lines 2-5 of the table), the contrast between the periods of upward and downward price trends is not much diminished.

How should the association between the price trends and the relative duration of business cycle phases be interpreted? With prices in the short run being less than fully flexible, fluctuations in aggregate demand, whatever their causes, will be met in part by output movements, in part by price adjustments. As a result, cyclical changes in output and prices will tend to be positively correlated. Beyond that, actual and expected price-level rises may temporarily stimulate economic activity if they are perceived as favorable movements in relative prices and profits, and analogously price-level declines may be discouraging if taken as siqnals of adverse changes in the same variables. But these can only be very short-lived effects insofar as they depend on misperceptions of general for relative price movements due to information lags. Propagation mechanisms that may amplify and prolong the consequences of such errors have been suggested, however, and views on the matter are still divided, as reflected in the recent debates on the equilibrium models of business cycles (zarnowitz, 1984). But few have argued that long-run trends in the level of prices have clear and lasting effects on real activity, or that secular infla- 
tion is necessary for economic growth. There is essential agreement that the long price movements reflect mainly trends in money and credit creation which have no definite, permanent effects on the evolution of the economy in real terms.

Indeed, there appears to be no association between the rate of inflation during each business cycle and the relative length of expansion versus contraction. The E/C ratios for the two cycles between 1953 and 1960 ( 3.9 and 3.0 ) were not unlike the ratio for the $1973-80$ cycle $(3.6)$, but inflation averaged a little over one percent per year in 1953-60 and 9 percent per year in 1973-80. GNP in constant dollars advanced at similar average annual rates in the two periods (2.6\% and 2.8\%), while unemployment increased from 4.9\% in 1953-60 to 6.6\% in 1973-80. As is well known, growth in the supply of money and credit accelerated sharply in the intervening twenty years; this resulted in more inflation and higher interest rates without stimulating the economy and reducing unemployment.

Prices tend to move up briskly when expansions gather steam, particularly in the boom phases at high levels of capital and labor utilization; they often used to decline and now typically rise more slowly in business contractions, particularly long slumps. This reflects both the cyclical fluctuations in aggregate demand and the typical reactions of businessmen. In a recession, costs are cut, profit margins are pared, and discounts are given to move heavy inventories or prevent their costly accumulation. Failures increase and goingout-of-business sales at low prices multiply as well. Wages rise more slowly and are red:r $\geqq d$ here and there under the pressure of increased layoffs and unemployment. Costly overtime work is cut back or eliminated. Consumers become more economical and cautious, especially about borrowing and spending on durable goods. All of this works in the direction of lower prices or at least lower 
inflation rates. Thus it is not surprising that the trends are toward less inflation (or more deflation) in periods during which business contractions are relatively long and frequent, and that the converse applies to periods dominated by expansions (see also Moore, 1983, chapters 14 and 15).

Thus it is not the long inflations that should be credited with shortening recessions and lengthening expansions; rather the opposite chain of influence deserves to be considered, in combination with the multiplicity of factors that would historically account for the shifts in the relative duration of business cycle phases. These include money and credit trends and financial innovations; changes in the structure of production, employment, and markets; changes in economic policies, institutions, and regulations; and major external shocks such as wars, financial crises, large failures, explosions and collapses of basic commodity prices, gold discoveries, etc. To apportion these influences to the observed shifts in the nature of business cycles would surely be an important but massive research undertaking which cannot be attempted here.

\section{v. The Reduced Severity of Recessions Since World war II}

The limitations of the available time-series data make it difficult to measure the amplitude of business cycles, particularly over long historical periods for which there are few monthly or quarterly statistics as comprehensive as such current indicators as real GNP, personal income, manufacturing and trade sales, employment, etc. To compare the size of recent expansions and contractions with those of the more distant past, about the best we can do is to use indexes of business activity or production and nonagricultural employment (Table 4).

\section{Table 4}

These comparisons are inevitably crude because of compositional shifts in the available measures of business activity and employment. 5 In particular, 
factory or manufacturing employment (used before 1929) is typically more variable over the business cycle than total nonagricultural employment which inludes a large and rising share of the relatively stable services (see next section). But such differences in the data probably account only in part for the large contrasts observed between the averge percentage amplitudes in Table 4. These measures are much smaller for 1945-82 than for 1912-45 or 1914-45. The cyclical movements in busines activity and employment were also on the average smaller in 1885-1912 or 1891-1914 than in the period during and between the two world wars, but by much lesser margins.

The ranking of the three subperiods is the same for expansions and contractions but the relative differences between the average amplitudes are greater for contractions. The exclusions of the wartime cycles does not alter the qualitative findings just summarized ( $i$ ts main consequence is to reduce the average expansion amplitudes for the periods concerned). When the amplitudes of expansions and contractions are added without regard to sign, the results once more confirm the shifts toward smaller movements of production and employment after 1945, for both all and peacetime cycles (columns 1, 3, and 5).

The cyclical movements in the series covered were in general less variable in 1945-82 than in the earlier periods, as indicated by the standard deviations of the individual amplitude measures (columns 2, 4, and 6). This applies strongly and without exceptions to the comparisons with 1912-1945 or 1914-1945.

What these measures suggest, then, is that business contractions have been on the average milder in the post-world war II era and also that their depth varied less across the recent cycles than it did in earlier times. These findings parallel those on the shorter and more uniform durations of the recent contractions as reported in section III above.

The moderation of business cycles, manifest in the relatively brief, mild, 
and infrequent recessions of the 1950s and 1960s was clearly an international phenomenon. Fxtraordinarily long and vigorous expansions occurred in Japan, West Germany, France, and Italy. One presumed reason lies in unique initial conditions. The end of the war found Europe and the Far East economically in stages of unprecedented exhaustion. Yet the war left behind not only the ruins of much of the physical capital of industry and commerce but also huge backlogs of unutilized and skilled human resources and unsatisfied demand. What followed was an era of Great Reconstruction: first a restoration of sound currencies and free markets, then rapid growth of employment, output, investment, and trade. Cyclical setbacks assumed for some time the form of retardations of growth rather than absolute declines. The U. S. economy, starting after the war from so much higher levels, intact and very strong, grew more slowly than Japan and Western Europe (other than the United kingdom). 6 Here mild contractions continued to recur, although the expansion in the 1960 s persisted beyond all previous experience and expectations.

This record suggests the hypothesis that higher rates of real growth, which prevailed in many countries in the first quarter century after 1945 under conditions favoring capital formation and international trade and development, tend to be associated with less cyclical instability. We shall examine the U. S. evidence on this point in section IX below.

Another type of partial explanation relies on structural changes that make the contemporary highly developed economies less recession prone. Trends in the industrial composition of employment illustrate such changes (Section VI). Shifts in the structure of personal income provide another example (section VIII). Here post-depression reforms concerning taxes and transfer payments which act as "built-in stabilizers" have played an important role.7

There are still other general hypotheses which are by no means incompatible 
with those noted above. Probably the one most discussed is that discretionary demand management has become more sophisticated and effective in reducing cyclical instability. This is obviously a critical issue but also one very difficult to test. Most observers would likely agree that some successes were scored by U. S. monetary and fiscal policies in the 1950 s and 1960 s but that the record was mixed and marked by increasing errors on the inflationary side. The topic will not be pursued here.

VI. Structural Shifts in Employment and Their Cyclical Effects The share of $\mathrm{U}$. S. employment accounted for by agriculture dropped from 48 percent in 1869 to 21 percent in 1929 and 4 percent in 1970. Business cycles have contributed to major swings in food prices but they have weak effects on the number of persons engaged in, and total output of, farming. Business cycles are to a large extent a product of industrialization. Despite the great importance of the strong downward trend in agricultural employment, we shall concentrate on shifts in the industrial composition of nonagricultural employment, for two reasons. (1) In recent times, the changing nature of business cycles has been strongly influenced by these shifts, much less so by the developments in agriculture, partly because the percentage employed in farming, though still declining, has already reached very low levels. (2) over the longer run, the huge shift away from agriculture would overshadow the trends we wish to examine.

Table 5 shows that in total nonagricultural employment, the combined share accounted for by manufacturing, mining, construction, and transportation, communications, and public utilities was stable in 1869-99 at about 568 but declined steadily to $48 \%$ by 1929. In the five cycles between the peaks of 1929 and 1957, that share fluctuated in the narrow range of $438-46 \%$, but in the next five cycles, 1957-81, it fell steadily from $42 \%$ to $33 \%$. The gainers included 
trade, insurance, real estate, personal and business services, and government-all service industries in the broad sense. This sector as a whole employed $44 \%$ of all persons engaged in nonagricultural production in $1869,51 \%$ in 1929 , and 67\% in 1979-81 (cf. columns 9 and 10 in Table 5).

Table 5

In the present context, the importance of this strong trend in the composition of employment rests on the fact that the rising industries have been much less recession-prone than the declining industries. The net result was a substantial reduction in the sensitivity of total employment to cyclical fluctuations in aggregate demand.

Table 6 provides the evidence. The average drop in employment during the recessions of 1948-82 varied from $10 \%$ per year for durable manufactures to 4-5\% for the other sensitive industries: nondurable manufactures, mining, construction, and transportation, etc. In trade, the declines averaged less than $1 \%$, and in services, finance, and government employment actually increased by about 28, so these industries have been more resistant to cyclical declines (column 3 ). Table 6

When the first four post-World war II contractions (1948-60) are separated from the last four (1970-82), some shifts in detail are observed but the same division between the relatively recession-prone and recession-proof industries holds (columns 1 and 2). Indeed, employment in most of the latter decreased much less or increased much more during the recessions of 1970-82 than during those of $1948-60$.

If the 1959 distribution of employment among the nine major industries had prevailed in the four recessions of 1948-60, the average reduction in nonagricultural employment would have been (other things equal) 2.5 percent. For 197082, the corresponding estimate is 2 percent, for all eight contractions 1948-82 
it is 2.3 percent. With the 1969 distribution, the reductions would have been $2.3,1.8$, and 2.0 percent for 1948-60, 1970-82, and 1984-82, respectively. with the 1982 distributions, the estimates are $1.7,1.0$, and 1.3 percent.

Between 1929 and 1959 shifts of this type were probably much less important, as Table 5 suggests. Now we see that they had significant effects between 1959 and 1969 and much stronger effects between 1969 and 1982. Will they endure as a source of employment stabilization in the future? Ten years ago the J. $s$. Bureau of Labor Statistics made projections to 1985 which assumed that the share of government and private service industries would continue to increase. Their most recent projections to 1995, however, imply a cessation (but not a reversal) of the overall shift toward the more recession-proof industries (Table 6, column 7). The rise in personal and business services is expected to be offset by a relative decline in government employment.

The expansion of the share of government in the economy persisted so long that even many who deplore this development regard it as nearly inevitable ("Wagner's Law"). Yet it is not a natural, irreversible tendency and forces opposed to it may be getting stronger.

The demand for services generally is often hypothesized to be more incomeelastic than the demand for goods, but Fuchs (1968, pp. 3-5) noted that the proportion of services in total output was the same in 1965 as in 1929 . He suggested that the shift of employment from Industry to service is explained largely by the higher labor requirements in the latter sector. Output per worker grew much more slowly in the production of services than in the production of goods. 8 But real output of services, and therefore productivity, is difficult to measure and often poorly estimated. The notion of a continuing shift into less productive industries and occupations seems worrisome and hard to reconcile with competitive markets. In the current controversy on new 
industrial policies, proponents urge a government-supported

"reindustrialization" drive which, they claim, would make the U. S. economy more productive and more competitive internationally. If this reverses the trend described above, however, the consequences for cyclical stability may offset some of the benefits.

VII. Trends and Cyclical Changes in Unemployment and Labor-Force Participation

Although the risk of losing a job has been reduced by the shift in the industrial composition of employment, the unemployment rate fluctuated around a rising trend since the late 1960 s. In this period shifts of product demand and derived labor demand between specific markets, industries, and occupations were accelerated by several developments, notably the intensification, fading, and end of the Vietnam war; the oil price increases; the swift spread of new products and technologies (computerization); the decline of some old industries such as steel prompted in part by increasing competition from imports. The unusually large intersectoral shifts contributed to the increases in unemployment (Lilien, 1982). In addition, other noncyclical factors probably operated in the same direction. The composition of the labor force shifted toward greater participation by women and teenagers, groups with relatively high rates of labor market turnover and unemployment. Higher unemployment benefits and wider coverage have probably added to the average time spent in job search and hence to the average duration and rate of unemployment. At the same time, the percentage of the working-age population employed has risen, reaching a peacetime record high in 1979 .

in the recession of 1981-82, the highest attained rate of unemployment was 10.8\%, exceeded only by the maximum rate reached during the major depressions of 1920-21 (not much higher) and 1929-33 and 1937-38 (which were extraordinarily high). On the other hand, the increase in the unemployment rate in 1981-82 was 
not particularly large. Jobless rates in recent contractions were generally much higher than in previous contractions of comparable size, 1923-24 and 192627. This can be seen clearly in Table 7, which compares the duration, depth, and diffusion of $\mathrm{U}$. S. business cycle contractions since 1920, using measures of production, employment, and unemployment.

Table 7

The measures are highly but far from perfectly correlated (see the matrix of the correlation coefficients in Table 7). Of course, unemployment changes and levels are inversely associated with the declines in real GNP, industrial production, and nonfarm employment. The measures of depth or amplitude (columns 2-6) are most closely related to each other, but the correlations involving duration and diffusion (columns 1 and 7 ) are also significant.

Comparisons of these and other statistics suggest that four mild recessions occurred during the 62 years covered in the table, one in the 1920s (1926-27), and three since 1960 (1960-61, 1969-70, and 1980). There were six sharp recessions, all but one (1923-24) in the post-World War II period (1948-49, 1953-54, 1957-58, 1973-75, and 1981-82). The three major depressions go back to 1920-21 and the 1930's: the "Great Depression" of 1929-33 was in many respects unique, and by far the most severe according to all measures. The 1945 recession was also quite particular because of its timing (end of world war II) and nature (transition back to peacetime production). It was brief and mild in terms of unemployment, sharp in terms of the decline in industrial production. The ranks in Table 7 , column 8 , based on the averages of the ranks of the entries in each of the columns 1-7, ag with the above classification. The only ambiguity refers to the sui generis 1945 reconversion episode.

An important caveat should be entered at this point, namely that there is no way to construct a really satisfactory single measure of the severity of 
recessions. Cyclical movements are complex and differentiated in terms of duration, diffusion, and depth. Some are relatively short but large and pervasive, e.g., the business contraction of 1937-38; others are of similar length but small and less widely spread, e.g., the recessions of 1960-61 and 1970. The use of average ranks is a crude approximation procedure, which is further aggravated by the gaps in the data. Nevertheless, the results appear to be sensible in that they agree with much broader evidence from historical and statistical studies. We have experimented with other data without finding any good reasons to alter our conclusions. 9

Coming back to the unemployment rate, it is the change in, rather than the level of, this variable that deserves most attention as an indicator of relative cyclical performance. The level attained during a recession is influenced in part by the level reached during the preceding expansion--i.e., it combines a measure of the weakness of the preceding expansion with the severity of the recession. Moreover, the level is influenced by trends in the age-sex composition of the labor force, as illustrated by the following results from a BLS study.10

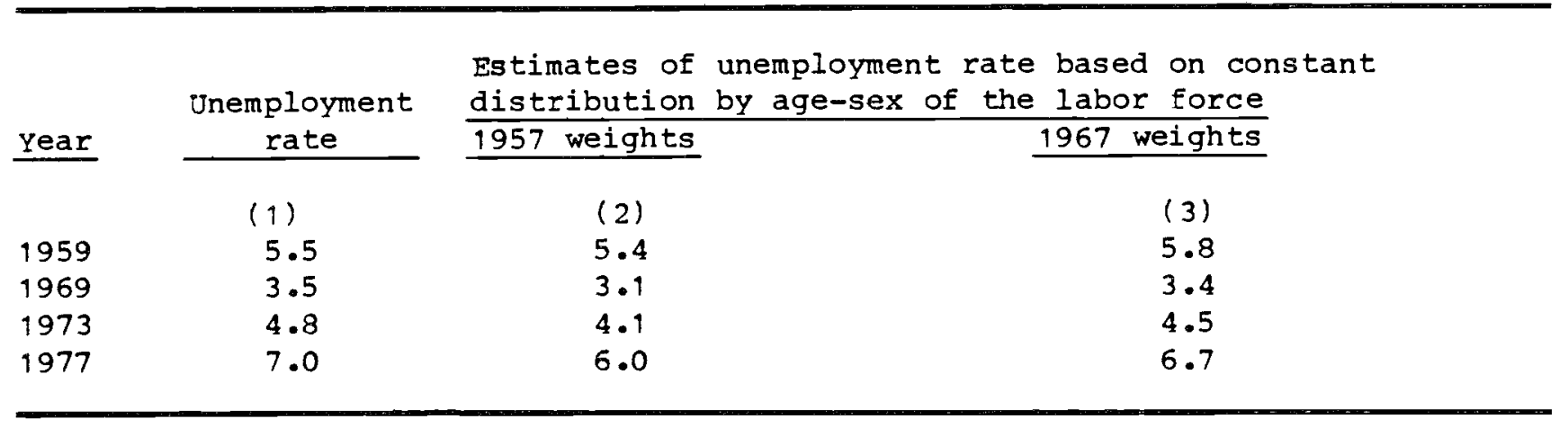

The rise in unemployment rate between 1959 and 1977 would have been much smaller if the age-sex composition of the labor force had remained as it was in 1957 or in 1967. Over the short periods encompassed by recession, however, these demographic changes are much less consequential, hence the change in the 
rate during a recession is less affected by these shifts and more by factors related to the severity of the recession itself.

In addition, it is important to consider the sensitivity of the labor force itself to changing market conditions and the implications this has for the interpretation of the unemployment measures. In a recession, some additional workers enter the labor force to bolster declining family incomes. At the same time, some unemployed, frustrated in their job search, withdraw from the labor market. Indeed, when the prospects for finding work at good wages appear to be poor, they may not even compensate for the expected search costs, so some wouldbe new entrants or reentrants will not even commence looking for jobs. Here as elsewhere, then, income and substitution effects can coexist in practice as well as theory, and the empirical question is which prevails. The evidence is that the civilian labor force, apart from its dominant upward trend, tends to respond positively to business cycles. That is, the "discouraged workers" effect generally outweighs the "added workers" effect.

The elasticity of the response of the labor force to cyclical changes in the demand for workers is in the aggregate not high, perhaps about 0.2 on the average (Mincer, 1966, p. 88). Much more sensitive are those groups that are typified by relatively weak (but growing) attachment to the labor force, namely women and youth (especially working wives and students). on the other hand, the participation rate of adult men declined fairly steadily from $89 \%$ in 1948 to $78 \%$ in 1983. Among older men, age 45 to 64 , earlier retirement became financially more attractive and increasingly frequent in the 1960 s and the downward movement in labor force participation accelerated in the 1970 s (e.g., it was 928 in 1960 , $90 \%$ in 1968, and $86 \%$ in 1984; see Bednarzik and Klein, 1977, p. 8).

It has been suggested that, when combined, all these shifts in composition "imply an over-all trend toward an increasingly sensitive, variable, and flex- 
ible labor force" (Mincer, 1967, p. 17). As the labor-force responsiveness of a group rises, the cyclical amplitude and conformity of its measured unemployment rate declines. Entries and reentries become more frequent during expansions when search costs are low and job conditions favorable. Entry rates decline and withdrawals rise when business is sluggish, reducing the labor force. Hence the change in unemployment may understate the true loss of potential employment and output. According to some indirect estimates, based on regressions of the labor force on cyclical indicators such as the employment-population ratios, the "hidden unemployment" was large indeed under relatively adverse labor-market conditions (several million people in the early 1960s). But the estimates indicate a heavy concentration of this phenomenon in the categories of "secondary" workers who spend a relatively high proportion of time outside the labor force. Many of these people time their decisions to enter or withdraw in reaction to changes in labor demand as well as supply and other relevant factors. Still, to some extent the labor force variation reflects also the tendency for discouraged workers to disappear in business expansions and reappear in contractions (Mincer, 1966, pp. 100-105; 1967, pp. 16-20).11

The percentage of the working-age population employed is very differently affected by these factors than is the unemployment rate. In 1983, for example, almost exactly the same percentage of the working-age population (16 years and over) was employed as in 1973, namely 58.3\%. (In these calculations, employment includes resident Armed Forces.) Other data, such as real personal income per capita or real compensation per hour, indicate that both years were about equally prosperous, but the unemployment rate in 1983 was nearly twice as high as in $1.973,9.58$ compared with $4.8 \%$. If calculated as a percentage of the working-age population instead of the labor force, unemployment was more than twice as high, $6.1 \%$ compared with $2.9 \%$. What happened was that a massive shift occured in the disposition of the population to seek jobs. This pushed up the 
unemployment rate but did not signify any great change in the availability of jobs per capita, which is measured by the employment percentage. Since the two measures do not always give the same message regarding employment conditions, it is important to consider both in evaluating the severity of recessions.

VIII. Changing Sources of Personal Income and the Business cycle According to annual estimates by Creamer (1956, p. 126), personal income in constant dollars fell during five business contractions and rose during three in the period 1910-38. The average of these changes was -5.0 percent. Corresponding annual measures for the eight business contractions of 1948-82, based on the present Department of Commerce data, show a reverse picture: three declines and five rises, averaging t0.7 percent. Hence, real income has become far more stable during business cycles since world war II than before.

The composition of personal income by major types and sources shows that several long-term shifts have contributed to this increasing stability (Tables 8 and 9). Wage and salary disbursements of government rose most of the time, accounting for 5 to 6 percent of total income in the business cycle peak years 1913 and 1929, but more than twice as much--11 to 14 percent--in the peak years of 1953-81. Transfer payments rose most strongly and persistently, from less than 18 of the total in 1929 and before to 198 in 1981 . The relative decline in farmers' income, from 108 in 1913 to 18 in 1981, was slow in the first half of the period covered, rapid in the second half. Nonfarm proprietors' income also fell decisively in relative terms, from $15 \%$ to $4 \%$. Wages and salaries in the private sector, by far the largest component of personal income, increased from 488 in 1913 to $58 \%$ in 1953, then fell back again to $48 \%$ in 1981 . 
of the types of property income, the shares of two show downward trends: dividends (6-7 percent in 1913-17, 2-4 percent thereafter) and, particularly, rent (from $11 \%$ down to 18 between 1913 and 1981). The proportion of interest income fluctuated roughly between $3 \%$ and $6 \%$ in the peak years 1913-53 but grew from $6 \%$ in 1960 to $8 \%$ in 1969, then rapidly to $13 \%$ in 1981 during the period of high inflation.

Table 9 classifies these types of income into two groups: those that have been relatively recession-proof and those that have been recession-prone. In general, the categories whose shares increased have been relatively recessionproof (interest, rental income) or even countercyclical (transfers), while the categories whose shares drifted mostly downward have been generally recessionprone (proprietors' incomes and wages of private workers). Income of government employees and transfer payments did not decline even in the severe depression of 1937-38 and neither did rent, while the downturn in interest income was moderate. Although dividends fell sharply in 1937-38, they often resisted the milder recessions in the post-World War II period (but note their drop in 1981-82). Labor income in the private sector typically declined at least moderately in recessions, mainly due to wages. It should be noted that the measures for 193738 and 1948-49 (columns 1 and 2) are based on data in current dollars, the measures for the 1948-80 averages and 1981-82 (columns 3 and 4) on data in constant dollars. It was, of course, necessary to adjust the recent figures for the effects of high inflation which masked the cyclicality of the nominal income series during most of the post-World war II era.

\section{Table 9}

Suppose the cyclical changes in each of the sources of personal income were as observed and taken to be independent of the shifts in the distribution of the aggregate. How would the changes in the composition of income by sources influ- 
ence the movements of total income under this assumption? The answer given by the estimates in the bottom section of Table 9 is "strongly." For example, had the relative importance of the main categories of income been the same in 1981 as in 1948, the reweighted decline of real personal income during the 1981-82 recession would have been 4.3 percent instead of the actual $7 / 10$ of one percent (column 4). Using the 1948 weights would have doubled the relative amplitude of the average decline in real personal income in the seven recessions of 1948-80, from the observed 1.1 to the estimated 2.3 percent (column 3 ). Conversely, the 1937-38 decline, which was actually 7.7 percent, would have been ceteris paribus only 4.1 percent under the distributional conditions of 1960 and 1.2 percent under those of 1981 (column 1)!

To be sure, hypothetical calculations of this type must be interpreted with great caution. The critical assumption that the amplitude of income change for each category is independent of the compositional shifts could be undermined by various factors. For example, transfer incomes may support consumption but their strong upward trend, with its implication of rising tax burdens, may at some point damage business confidence and investment. The rising share of interest income reflects increasing and high interest rates, which again can have strong adverse effects on government finance, security markets, and, most important, real capital formation by business firms and households. The expansion of government employment, in relative as well as absolute terms, contributes to the taxpayers' burden. And there are still other possible complications which the simple global estimates in Table 9 neglect: it may be $\therefore$ Dortant to separate the effects of changing compensation rates and input volumes and to take account of flner distinctions, e.g., the relative importance of durables, nondurables, and services in generating personal income. These qualifications were already made by Creamer and Moore in 1956. Nevertheless, as projected in that volume nearly thirty years ago, fluctua... 
tions in income that accompany business cycles did moderate significantly, and there can be little doubt that the trends in the composition of personal income by major types and sources made a substantial contribution to this development. 12

IX. Growth Rates and Variability of Economic Chanqe

Although it is true for the period since 1945 as a whole that contractions have become shorter and milder, there is nonetheless a useful distinction to be made between the first two decades and the next one. In the 1950s and 1960 s high long-term growth rates prevailed in the U. S. economy as well as among its major trading partners. Domestically, high inflation was not yet perceived to be a persistent and grave problem with no easy, apparent solution, and neither was high unemployment so perceived. Looking back, contemporaries had little doubt about the contrast between these economically rather placid and prosperous decades and the turbulent times that followed, dominated by seemingly uncontrollable inflation, more frequent and serious recessions, energy problems, and financial instability.

To put such impressionistic comparisons on firmer ground, Table 10 divides the U. S. economic record since 1903 into six periods each covering from two to four complete business cycles measured from peak to peak. Three of these show average annual growth rates in real GNP ( $g$ ) varying from 3.4 to 3.9 percent: 1903-13, 1923-29, and 1948-69. The other three are characterized by considerably lower long-term growth ranging from 2.4 to 2.8 percent per year: $1913-23,1929-48$, and 1969-81 (column 7).13

Table 10

To measure relatively high and low economic stability, we use standard deviations of the annual growth rates in real GNP ( $)$. It turns out that variability in growth was generally greater in the slower growth periods (columns 7 and 8). In addition, the more recent periods in both groups showed 
less variability than the earlier periods, confirming the point made above regarding the reduced severity of recessions since World War II.14

It is also of interest to observe that the proportion of time spent in contraction was 158 in $1948-69$ and 248 in 1969-81. Even this last figure is much lower than the corresponding statistics for the earlier periods (cf. columns 4-6). These measures indicate no correspondence between the average growth rates and the relative duration of contractions. Thus in 1903-13 and 1923-29, when growth was relatively high, the percentage of time accounted for by business contractions exceeded that in 1929-48 and 1969-81, periods with lower growth. Strong inflationary trends prevailed in 1913-23 and 1969-81, when monetary aggregates expanded rapidly but real growth was relatively weak. In the other periods, inflation was fairly moderate or absent. The following tabulation shows the average annual growth rates $(z)$ in real income, the stock of money, nominal income, and the implicit price deflator $(g, m, y$, and $p$, respectively.15 The periods with relatively high real growth (on the left) had on the average lower $m, y$, and $p$ rates than the periods with lower real growth (on the right).

\begin{tabular}{llllllllll}
\hline & $\underline{\mathrm{g}}$ & $\mathrm{m}$ & $\mathrm{y}$ & $\mathrm{p}$ & & $\underline{\mathrm{g}}$ & $\frac{\mathrm{m}}{\mathrm{p}}$ & $\frac{\mathrm{y}}{1}$ & \\
$1903-13$ & 3.4 & 6.1 & 5.4 & 2.0 & $1913-23$ & 2.4 & 8.8 & 8.2 & 4.9 \\
$1923-29$ & 3.5 & 4.1 & 3.4 & -0.2 & $1929-48$ & 2.5 & 5.3 & 4.2 & 2.0 \\
$1948-69$ & 3.9 & 4.7 & 6.2 & 2.3 & $1969-81$ & 2.8 & 9.7 & 10.0 & 7.0 \\
Average & 3.7 & 5.0 & 5.0 & 1.4 & Average & 2.6 & 7.9 & 7.5 & 4.6 \\
\hline
\end{tabular}

$\mathrm{x}$. Changes in the Cyclical Behavior of prices

Reference cycle patterns provide a simple and useful device for describing the movements of a series during buiness cycles. The series is divided into 
segments, each of which covers one business cycle dated from the initial to the final trough. A pattern consists of nine averages, one for each of the consecutive stages of the cycle. Stages I, V, and IX are three-month periods centered on the initial trough, peak, and terminal trough of a business cycle, respectively. Stages II, III, and IV cover successive thirds of the expansion,(trough to peak), and stages VI, VII, and VIII cover similar portions of the contraction (peak to trough). All measures are in "reference cycle relatives," that is, percentages of the average standing of the data during the given business cycle. The procedure retains the intra-cycle trend but eliminates the inter-cycle trend because the average relative for each cycle is 100 . It should be noted that reference cycle stages differ in duration as do the individual business cycles. For certain purposes, therefore, such as comparisons of leads and lags at turning points, measures in fixed calendar-time units may be preferable. But an analysis of the patterns can be very revealing in some contexts. This is so in particular with respect to the identification of any major and persistent changes in broadly defined cyclical movements, which is our concern here.

We have plotted and inspected 30 reference patterns for U. S. wholesale prices, one for each of the complete business cycles since 1854. The first impression is one of great variability, but a closer analysis helps to explain the main differences and bring out the more persistent traits. The intra-cycle portions of the longer trends are often strong enough to have pronounced and readily visible effects. Thus in 1854-61 a downward local drift came to dominate the longer upswing in prices, and then between 1864 and 1896 there was a long downswing which however flattened temporarily in 1885-91. ${ }^{16}$ Accordingly, the seven patterns covering the periods 1854-61, 1867-85, and 1891-97 have clear 
downward tilts. Between 1896 and 1920 prices tended to move up, with some levelling off in 1910-14. This left an impress upon the several corresponding patterns. The weakness of prices in 1920-32 shows up in the downward-tilted patterns for this period, and their subsequent upward trend in the upward-tilted patterns for the post-1933 cycles.

Major wars had huge effects on the behavior of prices. The patterns for 1861-67 (stages I-IV) 1914-19 (I-VI), and 1945-49 (I-IV) show the surging inflations of the Civil War and World War I and the slower, more suppressed inflation of World war II. The inflations of the Korean and Vietnam wars are much less conspicuous in the patterns for 1949-54 (III-V) and 1961-70 (IIIIX). After the Civil war, a strong deflation followed immediately; after world War I, prices first stabilized but then fell sharply in the 1920-21 depression; but no strong downward movements in the price level trailed any of the later wars .

The most important findings are as follows. Virtually all business cycle contractions through 1938 were associated with some declines in prices during at least some of their stages. When the trend was down, these declines would of ten start during the expansions and last longer, but they would also typically accelerate after the peak stage (V). When the trend was up, the rising segments of the patterns tended to be larger and longer, frequently starting before the. trough and extending beyond the peak, but the contractions would still witness some significant price-level declines (mainly between stages $V I$ and IX). The only early patterns which show very weak and irregular price movements, in the 1885-91 period, refer in two short and marginal cycles, an interlude of relative stabil... ity separating major fluctuations dominated by strong deflationary developments in the early 1880 s and 1890 s.

The more recent cycles present a sharply contrasting picture. The brief 
and peculiar end-of-the-war contraction of 1945 was accompanied by essentially flat wholesale prices. This year saw the end of wartime price controls. The last contraction during which prices fell significantly occurred in 1948-49. The Korean expansion saw new partial wage and price controls and had a phase in 1951 during which prices declined considerably, but in the ensuing contraction they merely stabilized after a new bout of wartime inflation. The stability persisted through most of the 1954-57 expansion, too, but prices started rising again moderately late in the 1957-58 contraction and during the short recovery of 1958-60, which alarmed many observers since there was little evidence of excess demand. This ended with the recession of 1960 , and several years of relatively stable prices followed. With the intensification of the vietnam war in the mid-1960s, a new and much more intensive round of inflation began, which the 1970 recession and the 1971 wage and price controls slowed down but a little and for a short time. After the series of supply shocks in 1973-74 (sharp rises in prices of food, oil, and other raw materials worldwide, termination of $U$. $S$. price controls, and after-effects of the switch to floating exchange rates), inflation accelerated strongly late in the 1973-75 recession and again in the mid-stages of the 1975-80 expansion, partly due to new supply shocks. It took a protracted period of poor business conditions in the early 1980s (two contractions separated by a weak one-year recovery) to reduce the pace of inflation substantially. As a group, the post-world war II patterns, marked by an absence of any major absolute declines in prices, are strikingly different from any comparably large subset of earlier patterns where deflation associated with business contractions was the rule.

By averaging the individual reference patterns stage by stage over some sufficiently long period, one may hope to bring out the typical features in the cyclical behavior of the variable concerned. The assumption underlying the prom 
cedure is that such persistent traits indeed exist; the more valid this premise is, the more useful the method.

The upper panel in Chart 1 shows five average reference cycle patterns based on the measures for the overall wholesale price series used in Chart 1. The first pattern, for the seven cycles of 1867-97, reflects weak rises during expansion and strong declines during contraction: the typical behavior in a period of long-run downward trend in prices. The second, for the five cycles of 1897-1914, when the long drift was up, shows a longer and stronger rise and weaker decline. The third, for 1919-38 (5 cycles), shows very large and more symmetrical cyclical movements, with a relatively small downward tilt. The average for the 17 cycles, 1854-1938, omitting the war-related episodes, is a nearly symmetrical, slightly downward-tilted pattern rising between each of the stages $I-V$ and falling between each of the stages $V-I X$. In clear contrast, the averages for the seven cycles 1949-82 describe a steadily rising pattern, although one whose slope is definitely lower in the contraction segment V-IX than in the expansion segment $I-V$. In this period, the contractions were associated with a lower, but not a negative, rate of inflation. Similar results for the period since 1919 are obtained from an analysis of the index of wholesale prices for industrial commodities only (omitting farm products and foods). The average reference patterns for 1919-38 and 1949-82 closely resemble their counterparts for the all-commodity index.

\section{Chart 1}

Cagan (1975, p. 90) concluded that:

The failure of the aggregate index of wholesale prices to decline in the recessions of 1954 and 1958 and then again in 1961, which contrasted with the sharp declines of previous recessions, was a new phenomenon. 
Our results confirm this observation on the basis of longer series than those used by Cagan (his measures cover the period 1891-1970, ours 1854-1982).

It has'been suggested that the post-1969 change in the observed behavior was due to the convergence of downward rigidities due to the increased market power of firms over prices and of labor unions over wages. Whether such developments did in fact occur on a sufficiently large scale has been questioned by some authors but accepted by others (Cagan, 1975, p. 90; DeLong and Summers, this volume). Another hypothesis is that following the Employment Act of 1946 the successive administrations demonstrated their commitment to combating unemployment so that people came to believe that contractions long or severe enough to generate any persistent deflationary movements would be effectively prevented. This explanation, which appears to be generally consistent with the evidence, is closely related to the more recent emphasis on the effect of a credible policy posture on expectations of changes in the price level (Fellner, 1980).

It is difficult to measure anticipated rates of inflation, but their role is undoubtedly basic. Cagan compared the average annual rates of change in wholesale prices during the successive expansions and contractions (to be denoted $E$ and C) and computed the differences $C-E$. This procedure amounts to using the preceding expansion rates as (admittedly rough) proxies for the anticipations. In Table 11, we bring Cagan's results up to date. After 1949, prices ceased declining during contractions: the signs of $C$ change from negative to positive (see columns 3 and 7 ). The differences $C-E$ have consistently negative signs in the seventeen cycles from 1891 to 1958 (columns 4 and 8 ). The $C$ rates, even where positive or zero as in 1945, 1953-54, and 1957-58, were smaller than the $E$ rates. In the four cycles between 1958 and 1980, however, the $\mathrm{C}-\mathrm{E}$ differences turned positive as well. ${ }^{17}$ The price 
response measured in these terms declined consistently in each of the six successive business cyles 1945-75. Only in 1980-82 did C - E result in a negative sign, marking a decidedly disinflationary phase (column 8 ).

Table 11

The wholesale price data make it clear that the magnitude of the postWorld War II inflation in the United States was due, not to an intensification of upward price pressures during business expansions, but to the increased length of expansions and the new persistence of such pressures during contractions. The average percentage increases of prices per year were very similar in the prewar and postwar expansions 6.3 and 6.4 percent during 18911945 and 1945-82, respectively), but very different in the prewar and postwar contractions $(-6.4$ and 3.3 percent, respectively).

Prices have been very sensitive to the severity of business contractions. In 1891-1945, the wholesale price index fell at an average rate of $15 \%$ p.a. in the five major depressions (MD), at $48 \mathrm{p} . \mathrm{a}$. In the four severe recessions (SR), and at $6 / 10$ of $18 \mathrm{p.a}$. in the four mild recessions (MR). The corresponding average differences $C-E$, in percentage points, are $-21,-12$, and -6 . In 1945-82 there were no major depressions, but in the five severe recessions the price index rose $2 \% \mathrm{p} . \mathrm{a} .$, and in the three mild recessions it rose $5 \% \mathrm{p.a}$. The C - E differential was -6 for the five $S R$ and +1.6 for the three MR. Thus in both periods prices were responsive to the severity of business declines, but it is clear that the response to recessions of comparable severity decreased substantially.

Detailed studies of wholesale price changes in the nonwar recessions of the 1.920s and 1948-70 (Cagan, 1975) indicate that these results are not attributable to the changing composition of the index. However, many raw materials 
prices retained their usually high cyclical sensitivity.

In a recent analysis of a broad spectrum of price and wage series for selected periods (1900-14, 1923-29, and 1949-66), Schultze (1981) argued that until the 1960 s low inflation "norms" in the nature of inert rules of thumb dominated price-level expectations and behavior. In his comments, Fellner (1981, pp. 577-581) disputed this hypothesis partly on the ground that Schultze's sample includes mainly years in which prices had a mild upward trend (in 1923-29 there was a slight downward drift). Had longer and more continuous price series been used, they would have demonstrated more flexible behavior and supported the concept of more "rational" expectations. Indeed, the pre-1920 patterns (see Chart 1) seem to us to be broadly consistent with this view.

\section{Changes in the Cyclical Behavior of Interest Rates}

Short-term interest rates historically exhibited cyclical movements varying from moderate to very large relative to their average levels. During business cycles containing major booms or slumps and affected by financial crises, large monetary disturbances, or wars, fluctuations in rates have often been huge and sudden. Financial markets are particularly sensitive to all types of factors influencing business conditions, so it is well known and not surprising that short rates are typically more volatile than most other important variables. This is well established by an analysis of 27 reference cycle patterns that covers more than 120 years of U.S. business history.

The patterns for commercial paper rates, 1858-1932, show clear procyclical movements, consistent with the simple notion that the demand for credit tends to increase relative to supply in expansions and decrease in cuacractions. The single major exception was the long but slow 1933-37 recovery from the worst recorded depression, during which short rates continued to drop sharply. However, the characteristic timing of the rates was predominately lagging, 
particularly at peaks. Rough coincidences prevailed only at the peaks of 186073 and 1923-29. At troughs, the timing was on the average lagging as well but much less consistently so. A few of the patterns (1861-67 and 1888-91 in addition to those related to the depressions of 1920-21 and the 1930s) are quite different from all the others.

The patterns for the 3 -month Treasury bill rate in the seven business cycles 1949-82 have very large amplitudes which bespeaks heightened sensitivity to cyclical influences.18 They rise sharply during expansions and fall sharply during contractions but with much variability in timing. Thus their highest standings are in stages $T V$ (for the 1958-61 cycle), $V(1949-54,1961-70$, and 1980-82), VI (1954-58 and 1975-80), and VII (1970-75). Of course, in the postWorld war II period interest rates generally had rising long-term trends; these were mild in the 1950 s and 1960 s and strong thereafter, reflecting mainly the course of inflation and the corresponding adjustments of price expectations. In basis points, the fluctuations in interest rates were very small until the late 1960s, then steadily increasing to very large size. It is interesting to note that the amplitudes of the corresponding patterns do not show a similar trend. That is, relative to their average values in each cycle the movements of bill rates have been about the same in recent cycles as in the 1950 s and 1960s, whereas in terms of basis points they were small in the early years when the levels of the rates were low and large in the late years when the levels of the rates were high.

The average reference cycle patterns in Chart 2 bring out the shifts in amplitude and timing. There is a near symmetry of movement in the diagram for the four earliest cycles covered (1858-79). The averages for the eleven cycles, 1879-1919, show a rise from stage II to VI-VII and a contraction between stages VII and II, that is lags at both peaks and troughs. The pattern for the five 
cycles of 1919-38 is strongly downward-tilted, with a rise between stages III and $V$ only (a long lag at troughs). These movements have been large enough to put a strong imprint on the overall averages (compare the patterns for 1919-38 and 1859-1938). In contrast, the diagram for the Treasury bill rate in seven cycles, 1949-82, shows a very large rise between stages I and VI, and a somewhat smaller decline in the contraction stages VI-IX. The average swing in bill rates since 1949 has been much larger than the average swing in commercial paper rates before 1938 .

\section{Chart 2}

It is common knowledge that long-term interest rates fluctuate much less than short-term rates; it is perhaps not so well known that they do not conform as well to business cycles. Both properties can be inferred from a comparison of the corresponding reference patterns. In 1900-1914, for example, the only large cyclical movements evident in high-grade industrial bond yields are those associated with the crisis and severe depression of 1907: first a rise in stages III-VII of the 1904-08 cycle, then a decline continuing through most of the recovery from that depression. A somewhat similar sequence occurred in connection with the depression of 1920-21 and the subsequent recovery. The large irregular movements in the great contraction of 1929-33 with a late peak in stage VIII (1931), and the long, first rapid then slow decline throughout the 1933-38 cycle are also notable episodes.

The corporate bond yield patterns for the post-world war II years contain some very large shifts, mostly upward. The timing of these movements has varied widely, .ith rises occurring between the following stages in each consecutive cycle.

Cycles: $\quad \begin{array}{lllllll}1949-53 & 1954-58 & 1958-61 & 1961-70 & 1970-75 & 1975-80 & 1980-82\end{array}$

Stages: $\quad$ I-V I-VI I-IV II-VII III-VII III-VI VIII-VI 
Consistent with the generally rising trend in yields, lags occurred more frequently at business cycle peaks than at troughs.

Chart 3

The average reference patterns in Chart 3 provide a bird's eye view. The overall amplitudes of movement in long rates have increased greatly between 1900-38 and 1954-82,but it is the strong upward trend in the recent period that accounts for this change. Allowing for the trend would tend to eliminate this difference. The intra-cycle drift tended to be down in the period between the world wars, strongly up in the last thirty years.

Cagan (1966), comparing the behavior of a broad group of interest rates before World War I, the 1920s, and the 1950s, noted that they may have become increasingly sensitive, conforming to moderate business cycles with larger amplitudes and shorter lags. Our reference cycle patterns are not inconsistent with this result. Table 12 indicates that a shift in timing toward shorter lags and more frequent leads did occur in the early post-World War II period (194560), but that later the lags reasserted themselves. In 1961-82 the lags were generally longer than in 1919-29, for example. The lags of bond yields behind bill rates also increased between these two periods (compare the first and fourth lines in the "Averages" section). On the whole, lags have prevailed heavily in the timing at troughs for both bills and bonds, but at peaks bills usually led while bonds lagged. The individual timing comparisons show a high degree of dispersion.

XII. Changes in the Timing of Leading and Lagging Indicators Since the 1960s, a collection of ecoromic indicators that systematically lead, coincide with, or lag business cycle turning points has become widely usc. in current economic analysis. The selection of these indicators has been based upon historical measures of the kind employed earlier in this paper, as well as 
upon historical measures of the kind employed earlier in this paper, as well as upon hypotheses of economic behavior that yield plausible explanations of the observed leads and lags. Here we examine the historical record of two of the selected groups of indicators with respect to their timing at business cycle peaks and troughs.

The longest available record of the timing of the leading and lagging indicators during business cycles covers nearly a century. In Table 13 the median leads or lags of specific groups of indicators are shown for each business cycle turn between 1885 and 1982. The indicators in the leading group show an unbroken record of leads, while those in the lagging group lag at all except two peaks and three troughs. Moreover, when the turns in the lagging group are compared with the opposite turns in the business cycle, they lead at every turn, and by longer intervals than the leading indicators do. The economic relations between the lagging and the leading indicators are such as to make these results reasonable, according to the considerable literature that has been devoted to the subject (for a summary and list of references, see Moore, 1983, ch. 21). From 1885 to 1938, the timing record is based upon 75 leading and 30 lagging indicators, the classification having been determined in 1950. Since the classification was based on the prior record, it is not surprising that the leading group led and the lagging group lagged. But the consistency over the entire period was not controlled by the method of classification, nor was the relation between the opposite turns in the lagging and leading groups. For the period 1948 to 1982 , the record was based upon twelve leading and six lagging indicators selected in 1975. Again the prior record was examined in making the selection. As has been shown elsewhere, however, the behavior of a group of indicators selected in 1950, without benefit of the subsequent record, was qui t.e similar during 1948-75 to the record shown in Table 13 (Moore, 1983, ch. 24). 
At business cycle peaks the average length of lead of the leading group, 1885-1982, was seven months, with a standard deviation of six months. At troughs the mean and standard deviation were about half as large, four and three months, respectively. There is some evidence in the table that the leads at peaks have become longer and the leads at troughs shorter since 1948 than before (see below).

The lags of the lagging group average five months at peaks and seven months at troughs, with standard deviations of four and five months, respectively. When the turns in the lagging group are compared with the opposite turns in the business cycle, the leads that emerge are quite long, averaging 21 months at peaks and ten months at troughs. They are also quite variable, with standard deviations of twelve months at peaks and eight months at troughs.

What rable 13 reveals, then, is an almost unbroken sequence of turning points during successive business cycles over the past hundred years. In view of our finding in section III that the principal shift in the length of business cycle phases took place after world war II, it is of interest to examine the sequence before and after 1945, as in the following summary:

Average Interval in Months

$\begin{array}{lrcc} & 1885 & 1948 & 1885 \\ \text { A. Business cycle peak to peak in lagging indicators } & -1945 & -1982 & -1982 \\ 5 & 6 & 4 & 5 \\ \text { B. Peak in lagging indicators to trough in leading indicators } & 7 & 4 & 6 \\ \text { C. Trough in leadinq indicators to business cycle trough } & 5 & 3 & 4 \\ \text { D. Business cycle trough to trough in lagqing indicators } & 6 & 9 & 7 \\ \text { E. Trough in lagging indicators to peak in leading indicators } & 12 & 16 & 13 \\ \text { F. Peak in leading indicators to business cycle peak } & 6 & 10 & 7 \\ \text { A }+ \text { B }+ \text { C. Business cycle contraction } & 18 & 11 & 15 \\ \text { D }+ \text { E }+ \text { F. Business cycle expansion } & 24 & 35 & 27\end{array}$


Each of the intervals into which the business cycle contraction is broken by these turning points has become shorter, on average, while each of the intervals that constitute the business cycle expansion has become longer. This in itself supports the finding of a major shift in the length of business expansions vis-à-vis contractions, since the intervals between the indicator turning points (though not their sum) are independent of the business cycle chronology. One other noteworthy feature of Table 13 is the evidence that the lengths of the leads or lags at successive turning points are positively correlated. The correlation coefficients $(r)$ are as follows:

At Business Cycle peaks, 1887-1981 Trough in Lagging and Peak in Leading Peak in Lagging and Peak in Leading At Business Cycle Troughs, 1885-1982
All

Excluding

Observations $\quad 1933$ and 1937

The correlations are not high, but they are all positive, and they are about as high when opposite turns are compared as when like turns are compared. This gives some support to the hypothesis that cyclical influences run from the lagging to the leading indicators as well as from the leading to the lagging indicators (see Moore, 1983, ch. 23).

Apart from the shift toward shorter recessions and Ionger expansions and the associated shift in the intervals between turns in the indicators, the most notable feature of the record is the absence of major changes in the timing relationships among the groups of indicators.

\section{Summary and Conclusions}

1. Business cycle expansions in the United states became much longer and 
recessions much shorter after World War II than before. From 1846 to 1945 , expansions were one and a half times as long as recessions. From 1945 to 1982 , they were four times as long. Recessions also became more uniform in length. Total cycle durations from peak to peak or trough to trough show no significant trend.

2. Historically, expansions have been long relative to recessions when the long-run trend in prices was upward, and shorter when the price trend was downward. This is mainly because expansions generate more upward pressure on prices than recessions do. However, we find no association between the rate of inflation during each business cycle and the relative duration of the phases.

3. Business cycle recessions after world war II have been much Iess severe than before, as indicated by comprehensive measures of employment, production, and real income. Shifts in the industrial composition of employment, changes relating to unemployment and labor-force participation, and trends in the distribution of personal income by major sources and types have all contributed to that moderation.

4. Inflation was much higher in 1969-81 than in 1948-69, while real growth on the average was lower. In the past, periods of relatively low long-term growth tended to have relatively high variability of annual growth rates. However, the variability of economic change (measured by standard deviations of real GNP growth rates) can be judged low by historical standards in both $1948-69$ and 1969-81.

5. The average rates of inflation were very similar in the U. S. expansions before and after 1945 but much higher in the porwar than in the prewar contractions. The inflation of recent decades can be attributed principally to the (novel) persistence of upward price pressures in contractions, not to an intensification of such pressures in expansions. Wholesale prices have 
continued to show considerable sensitivity to the degree of severity of business contractions.

6. Short-term interest rates moved with very large relative amplitudes, high positive conformity, and variable timing in the business cycles of 1949-82. Before World War I their movements tended to be smaller relative to the cycle average, and they often had long lags at turning points. Long-term rates continued to lag behind the short rates most of the time, and to show much smaller amplitudes of movement and lower conformity to business cycles.

7. The longest available record of the cyclical timing of leading and lagging indicators covers nearly a century. Apart from a shift towards shorter recessions and longer expansions, and the associated shift in the intervals between turns in the indicators, the most notable feature of the record is the absence of major changes in the timing relationships among the groups of indicators.

We conclude that various structural, institutional, and policy changes contributed to the evolution of business cycles. The process is continuing. There have been important chanqes, yet the most basic characteristics and many outward manifestations of the business cycle remain much the same (as illustrated by the timing sequences of the indicators). The cyclical processes are sometimes stretched out and sometimes compressed, depending on long-term trends in growth, inflation, etc., as well as the nature, size, and frequency of outside disturbances.

More intensive research is very much needed on each of the topics we could address but briefly in this overview. In addition, there are other aspects of the changing nature of business cycles that we had to exclude. The most important of these are international. For example, greater conformity of U. S. exports 
to business cycles in recent times has been noted by Mintz, 1967, and Moore, 1974. Business cycles, and even major fluctuations in positive growth rates, appear to be rather integrated among the industrialized trading countries. The full implications of this fact remain to be analyzed. 


\section{NOTES}

1. The annals begin in 1790 for England and the United States, in 1840 for France, in 1853 for Germany, in 1867 for Austria, and in 1870 for twelve other countries on four continents. They end in 1925 (Thorp, 1926) and in 1931 (Thorp, 1932). The NBER chronologies start in 1792, 1834, 1840, and 1866 for Great Britain, U. S., France, and Germany, respectively. See Moore and Zarnowitz, 1984, in this volume, for more detail.

2. In contrast, seasonal (daily and annual) cycles, although influenced by custom, e.g., the timing of holidays, are in large measure part and parcel of the natural environment of man. Centrally directed or collectivist economies suffer from various types of instability induced partly by nature (e.g., variations in harvest) and partly by government and societal actions (e.g.. political purges; planning errors; imposition, resistance to, and relaxation of price and other controls). In reaction to such disturbances, the overall growth rates of these systems can vary widely over time, but such fluctuations are very different from business cycles, just as closed centralized economies are fundamentally unlike open market or "mixed" economies.

3. Consider also the classical theories of stationary state and the law of historically diminishing returns, as well as the Malthusian population principle, in the light of the great increase in the average standard of living in the densely populated countries of western Europe and Japan. A hundred years after Malthus, Veblen anticipated a convergence of modern economies to a chronic state of mild depression. Keynes sympathized with the intuitive underconsumption hypotheses of Malthus and Hobson as forerunners of his theory of deficient effective demand. For appraisals of current interest, see Mitchell, 1927, ch. IX; Keynes, 1936, ch. 23; Haberler, 1964 (1937), ch. 5; and Burns and Mitchell, 1946, Pp. 382-383. 
4. The monthly index of wholesale prices (warren-pearson, 1854-1891, and BLS, 1891-1933) rose in 13 out of 20 expansions and fell in 17 out of 20 contractions. Snyder's monthly index of the general price level, covering a broad assortment of prices (1861-1933) rose in 15 out of 18 expansions and fell in 13 out of 19 contractions. See Burns and Mitchell, pp. 98-101. For confirming detailed evidence on the behavior of wholesale prices since 1891, see Cagan, 1975, pp. 56-57

5. The Axe-Houghton index (used for the 1885-91 cycles) is based on pig iron production, imports, bank clearings outside New York City, and traffic revenue per mile for selected railroads. The Babson index (for 1891-1920) is a baseyear weighted aggregate of seasonally adjusted physical volume or constantdollar series, with coverage expanding from 11 to 33 components. It includes manufactures, minerals, agricultural marketings, construction, railway freight ton-miles, electric power and foreign-trade volume, weighted by value-added. The Federal Reserve Board index of industrial production (1920-82) initially includ. ed about 50 series. Its coverage increased over time to more than 200 series representing output in manufacturing, mining, and public utilities. The index of factory employment for 1891-1911 is based on data for Massachusetts, New Jersey, and New York (Jerome, 1926). The Bureau of Labor statistics index of factory employment (1913-1982) is based on a national sample of cooperating national establishments. The BLS series on nonagricultural employment (used after 1933) is based on monthly reports from a very large number of establishments (some 160,000). (For more detail, see Moore, 1961, vol. II; U. S. Department of Commerce, 1977.)

6. For example, the average annual growth rates of real GNP in $195 n-69$ were 3.98 for the United States, $6.8 \%$ for west Germany, and 5.38 for France. Japan's output grew 9.78 per year in 1952-69, Italy's 5.68 per year in 1951-69. The corresponding average for the United Kingdom, 1950-69, was 2.7\%. See U. S. 
Department of Commerce, 1973, p. 99.

7. Similarly, deposit insurance is believed to have strengthened public confidence in the financial system and prevented runs on the banks that were a major feature of the crises and some depressions in the pre-World war II era. on the other hand, there are some new sources of instability in this area, such as recurrent disintermediation, credit controls, and "credit crunches;" financial innovations and fluctuations in the demand for money and credit; and the uncertainties of current moves to relax banking and related regulations. 8. Thus the average annual rates of change in output per worker were 2.28 in Industry and $1.1 \%$ in service ( $3.4 \%$ in Agriculture). The classification here is much the same as in Table 6 , but Industry includes government enterprise (Service always includes general government). The corresponding statistics for 1959-82 are Industry 1.98 and Service 0.98 (based on BLS employment and BEA output data).

9. In particular, attempts to close the gaps in ranks run into problems of comparability. The declines in factory employment (BLS) rank the contractions of 1920-21, 1923-24, and 1926-27 in agreement with the labels MD, SR, and MR, respectively (they are, in percent, $-31.1,-13.7$, and -5.3 ). But factory employment has larger amplitudes than total nonagricultural employment. For example, the declines in $1929-33$ were -43.08 and -31.68 respectively; in $1937-$ $38,-21.2 \%$ and $-10.8 \%$. Real GNP also declined strongly between the years 1944 and 1946 (by some 16 percent), but changes in the composition of output in this period of transition from wartime to peacetime production make it difficult to interpret this development. 10. See Flaim, 1979, pp. 16-17. 
11. Over larger periods, labor force growth may respond directly to favorable economic conditions. Using the data in form of changes in percentage points per decade, Easterlin demonstrates that the contribution of net migration and participation-rate changes to labor force growth is inversely associated with the unemployment rate. For $1880-1965$, the correlation is -0.83 (Easterlin, 1968, pp. 151-153 and 257).

12. For further evidence, particularly concerning the role of government expenditures and transfer payments, see Beck, 1980, and Cullity, 1983.

13. See zarnowitz (1981, pp. 476-480) for a discussion of how these periods were selected, references to related literature, and an attempt to push the comparison back to 1882 .

14. Both 1913-23 and 1929-48 include large wartime expansions as well as major depressions (with the latter outweighing the former as regards growth effects but all contributing to high variability).

15. The measures for $1903-48$ are calculated from annual data listed in Friedman and Schwartz, 1982, Table 4 (following p. 121). They refer to the sum of currency held by the public plus adjusted deposits at all commercial banks; national income or net national product; and the corresponding implicit price deflator. The measures for 1969-82 are based on data on M2, GNP, and IPD as given in the Economic Report of the President, February 1984, pp. 220, 224, and $291^{\circ}$

16. For the chronology of the "Iong waves" in prices, see Table 2 . On the shorter "local" trends superimposed on these waves, see Burns and Mitchell, 1946, pp. 438-44n with Chart 65.

17. It should be remembered that these measures are averages in percent per year. Taking into account the different durations of expansions and contractions and the lengthening lags in prices, it is still true that some disinflation 


$$
\mathbf{F}-5
$$

accompanied or followed each of the recessions concerned.

18. Treasury bill rates have become a particularly important and sensitive indicator of money market conditions. Commercial paper rates have somewhat different characteristics than they used to have (Selden, 1963) but their reference cycle patterns since 1949 bear a fair family resemblance to the Trasury bill rate patterns. 


\section{References}

Baily, Martin N., 1978. "Stabilization Policy and Private Economic Behavior," Brookings Papers on Economic Activity, 1, pp. 11-60.

Beck, Morris, 1980. "The Public Sector and Economic stability," The Business Cycle and Public Policy, 1929-80 A Compendium of Papers submitted to the Joint Economic Committee, Congress of the United States, Washington, D.C.: 0. S. Government Printing office, pp. 105-129.

Bednarzik, Robert w., and Klein, Deborah P., 1977. "Labor Force Trends: A Synthesis and Analysis," Monthly Labor Review, vol. 100, no. 10 (October), pp. 3-12.

Bowers, Norman, 1981. "Have Employment Patterns in Recessions Changed?" Monthly Labor Review, vol. 104, no. 2 (February) pp. 15-28.

Burns, Arthur F., 1960. "Business Cycles," International Encyclopedia of Social Sciences, vol. 2, pp. 226-245.

, and Mitchell, Wesley C., 1946. Measuring Business Cycles. New York: National Bureau of Economic Research (NBER).

Cagan, Phillip, 1966. Changes in the Cyclical Behavior of Interest Rates. NBFR Occasional Paper 100. Reprinted in Jack M. Guttentag, ed., 1971, Essays on Interest Rates, vol. II. New York: NBER, pp. 3-34.

1975. "Changes in the Recession Behavior of Wholesale Prices in the $1920^{\prime} \mathrm{s}$ and Post-World War II," Explorations in Economic Research, vol. 2, no. 1 (winter), pp. 54-104.

Creamer, Daniel, 1956. Personal Income during Business Cycles, New York: NBER . With Foreword by Geoffrey H. Moore, pp. ix-xxxi.

Cullity, John P., 1983. "The Changing Structure of Personal Income and Business Cycles in the 1980's," New York: Center for International Business Cycle Research, Columbia University, unpublished paper (mimeo.)

DeLong, Bradford Jr., and Summers, Lawrence M., 1984. "The Changing Cyclical Variability of Economic Activity in the United States," NBER Conference on Business Cycles.

Easterlin, Richard A., 1968. Population, Labor Force, and Long Swings in Economic Growth: The American Experience, New York: Columbia University Press for NBER.

Fellner, william, 1980. "The Valid Core of the Rationality Hypothesis in the Theory of Expectations," J. Money, Credit and Banking, vol. 12, no. 4, part 2 (November), pp. 763-787. - 1981. "Comment" on C. L. Schultze, 1981.

Flaim, Paul O., 1979. "The Effect of Demographic Changes on the Nation's Unemployment Rate," Monthly Labor Review, vol. 102, no. 3 (March), pp. $12-23$. 
Friedman, Milton and Schwartz, Anna J., 1963. A Monetary History of the United States, 1867-1960, Princeton: Princeton University Press for NBER.

. 1982. Monetary Trends in the United States and the United Kingdom: Their Relation to Income, Prices, and Interest Rates, 1867-1975, Chicago: Chicago University Press for NBER.

Fuchs, Victor R., 1968. The Service Economy, New York: Columbia University Press for NBER.

Gordon, R. A., 1969. "The Stability of the U. S. Economy,"in Martin Bronfenbrenner, ed.. Is the Business Cycle Obsolete? New York: WileyInter-science, pp. 3-33.

Haberler, Gottfried, 1964. Prosperity and Depression, Cambridge, Mass.: Harvard University Press (new edition; first published by the League of Nations in 1937).

Heller, Walter w., 1967. New Dimensions of Political Economy, New York: Norton.

Jerome, Harry, 1926. Migration and Business Cycles, New York: NBER.

Kendrick, John W., 1961. Productivity Trends in the United States, Princeton: Princeton University Press for NBER.

Keynes, John M., 1936. The General Theory of Employment, Interest, and Money. London: Macmillan \& Co.

Kuznets, Simon, 1971. Economic Growth of Nations., Cambridge, Mass.: The Belknap Press of Harvard University Press.

Lilien, David M., 1982. "Sectoral Shifts and Cyclical Unemployment," J. Polit. Econ., vol. 90, no. 4 (August), pp. 777-793.

Mills, Frederick C., 1926. "An Hypothesis Concerning the Duration of Business Cycles," J. Amer. Stat. Ass. (December), pp. 447-457.

Mincer, Jacob, 1966. "Labor-Force Participation and Unemployment: A Review of Recent Evidence," in R. A. Gordon and M. S. Gordon, eds., Prosperity and Unemployment, New York: John Wiley \& Sons, pp. 73-112.

. 1967. "Research in Labor Force and in Unemployment," Forty-seventh Annual Report (June), New York: NBER, 16-22.

Mintz, Ilse, 1967. Cyclical Fluctuations in the Exports of the United States Since 1879, New York: NBER.

Mitchell, Wesley C., 1927. Business Cycles: The Problem and Its Setting, New York: NBER. 
Moore, Geoffrey $H_{.}$ed., 1961. Business Cycle Indicators, 2 vols., New York: NBER .

-, 1974. "Some Secular Changes in Business Cycles," Amer. Econ. Rev. (May), Reprinted as chapter 10 in Moore, 1983.

, 1983. Business Cycles, Inflation, and Forecasting, 2nd. ed., Cambridge, Mass .: Ballinger Publ. Co. for NBER.

Moore, Geoffrey H., and Zarnowitz, Victor, 1984. "The Development and Role of the National Bureau's Business Cycle Chronologies," NBER Conference on Business Cycles.

Personick, Valerie A., 1983. "The Job Outlook Through 1995: Industry Output and Employment Projections," Monthly Labor Review, vol. 106, no. 11 (November), pp. 24-36.

Sachs, Jeffrey, 1980. "The Changing Cyclical Behavior of Wages and Prices" 1890-1976," American Economic Review, vol. 70 no. 1 (March) pp. 78-90.

Schultze, Charles L., 1981. "Some Macro Foundations for Micro Theory," Brookings Pap. Econ. Act., no. 2, pp. 521-576.

Schumpeter, Joseph A., 1939. Business Cycles, 2 vols., New York: McGraw-Hill Book Co.

Selden, Richard T., 1963. Trends and Cycles in the Commercial paper Market. Occasional Paper 85, New York: NBER.

Thorp, Willard L., 1926. Business Annals, New York: NBER.

U. S. Department of Commerce, Bureau of the Census, 1973. Long Term Economic Growth, 1860-1970, washington, D.C.: U. S. Government Printing Office.

Zarnowitz, Victor, 1981. "Business Cycles and Growth: Some Reflections and Measures," Wirtschaftstheorie und Wirtschaftspolitik: Gedenkschrift für Erich Preiser, W. J. Mückl and A. F. Ott, eds., Passau: Passavia Universitätsverlag, pp. 475-508.

-, 1984. "Recent Work on Business Cycles in Historical Perspective," unpubl. ms. 
Table 1

\section{Duration of Business Cycles in the United States by Selected Subperiods, 1846-1982}

\begin{tabular}{|c|c|c|c|c|c|c|c|c|c|}
\hline \multirow[b]{3}{*}{$\frac{\text { Period }}{(1)}$} & \multirow{3}{*}{$\begin{array}{c}\begin{array}{c}\text { Number of } \\
\text { Business Cycles } \\
\text { Covered }\end{array} \\
(2)\end{array}$} & \multicolumn{6}{|c|}{ Duration in Months ${ }^{a}$} & \multirow{2}{*}{\multicolumn{2}{|c|}{$\begin{array}{l}\text { Percent of Time } \\
\text { in Contraction }\end{array}$}} \\
\hline & & \multicolumn{2}{|c|}{ Expansions } & \multicolumn{2}{|c|}{ Contractions } & \multicolumn{2}{|c|}{ Business Cycles } & & \\
\hline & & $\frac{\text { Mean }}{(3)}$ & $\frac{\text { S.D. }}{(4)}$ & $\frac{\text { Mean }}{(5)}$ & $\frac{\text { S.D. }}{(6)}$ & $\frac{\text { Mean }}{(7)}$ & $\frac{\text { S.D. }}{(8)}$ & $\overline{\frac{A l l}{(9)}}$ & $\frac{\text { Peacetime }}{(10)}$ \\
\hline \multicolumn{10}{|c|}{ All cycles } \\
\hline $1846-1885$ & 8 & 32 & 16 & 27 & 18 & 59 & 28 & 45 & 46 \\
\hline $1885-1912$ & 8 & 23 & 5 & 17 & 5 & 40 & 4 & 42 & 42 \\
\hline $1912-1945$ & 8 & 33 & 24 & 17 & 12 & 51 & 20 & 34 & 47 \\
\hline $1945-1982$ & 8 & 45 & 28 & 11 & 4 & 56 & 27 & 20 & 25 \\
\hline \multicolumn{10}{|c|}{$\begin{array}{l}\text { Excluding mar- } \\
\text { ginal recessions }\end{array}$} \\
\hline $1846-1885$ & 7 & 39 & 21 & 28 & 19 & 68 & 38 & 42 & \\
\hline $1885-1912$ & 6 & 36 & 21 & 18 & 5 & 53 & 21 & & 33 \\
\hline \multicolumn{10}{|c|}{ Summary } \\
\hline $1846-1945$ & 24 & 30 & 17 & 20 & 13 & 50 & 21 & 41 & \\
\hline $1846-1945^{C}$ & 29 & 36 & 21 & 21 & 14 & 57 & 27 & 37 & \\
\hline $\begin{array}{l}\text { 1846-1982 } \\
\text { Peacetime }\end{array}$ & cycles ${ }^{32}$ & 33 & 21 & 18 & 12 & 51 & 22 & 35 & \\
\hline $1846-1982$ & 27 & 28 & 13 & 19 & 12 & 46 & 18 & & 41 \\
\hline $1846-1982^{c}$ & 24 & 33 & 18 & 19 & 13 & 52 & 25 & & 37 \\
\hline
\end{tabular}

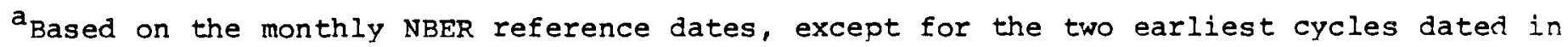
calendar years (troughs: 1846 and 1848, peaks: 1847 and 1853). Mean = mean duration; S.D. $=$ standard deviation, in months. Col. (3) $+\operatorname{col} .(5)=\operatorname{col} .(7)$, except for rounding.

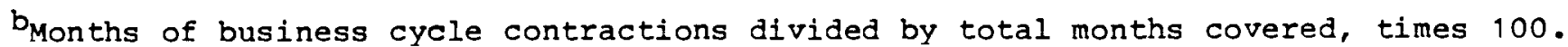

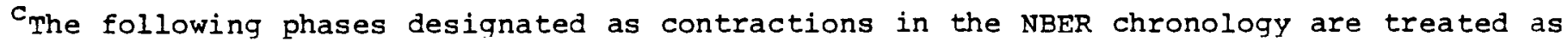
retardations rather than recessions and included, along with the preceding and following phases, in long expansions: 6/1869-12/1870; 3/1887-4/1888; 6/1899-12/1900. For detail, see Zarnowitz, 1981, pp. 494-505.

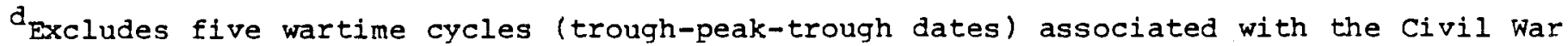
(6/1861-4/1865-12/1867); World War I (12/1914-8/1918-3/1919); World War II (6/1938-2/194510/1945); Korean War (10/1949-7/1953-5/1954); and Vietnam war (2/1961-12/1969-11/1970).

Source: National Bureau of Economic Research. For individual cycle durations, annual estimates for earlier cycles (1790-1845), and specific references, see , sore and Zarnowitz,. Tables 2,3 , and 5 , in this volume. 
Table 2

Long-Term Trends and Average Cyclical Changes in Prices, onited States, 1789-1982

\begin{tabular}{|c|c|c|}
\hline Trend in & Whol & Price \\
\hline $\begin{array}{c}\text { Directior } \\
\text { (1) }\end{array}$ & $\begin{array}{c}\text { Dates } \\
(2)\end{array}$ & $\begin{array}{l}\text { No. of } \\
\text { Years } \\
\text { (3) }\end{array}$ \\
\hline Rising & $1789-1814$ & 25 \\
\hline Falling & $1814-1843$ & 29 \\
\hline Rising & $1843-1864$ & 21 \\
\hline Falling & $1864-1896$ & 32 \\
\hline Rising & $1896-1920$ & 24 \\
\hline Falling & $1920-1932$ & 12 \\
\hline Rising & $1932-1982$ & 50 \\
\hline Total or & average & 193 \\
\hline
\end{tabular}

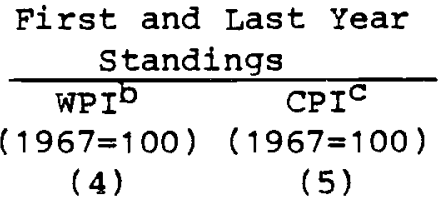

$\begin{array}{cc}30-64 & 30-63 \\ 64-26 & 63-28 \\ 26-68 & 28-47 \\ 68-24 & 47-25 \\ 24-80 & 25-60 \\ 80-34 & 60-41 \\ 34-299 & 41-289\end{array}$

\begin{tabular}{l}
$\begin{array}{c}\text { First to Last Year } \\
\text { Change ( } 8 / \text { year) }\end{array}$ \\
\hline WPId \\
$\begin{array}{lc}\text { (6) } & \text { CPIe }\end{array}$
\end{tabular}

$3 \cdot 1$
$-3 \cdot 1$

4.7

$-3.2$

5.1

$-6.9$

4.4

1.2
Average $\%$ Change in WPI (annual rate) $f$ Business Cycle Expansions Contractions

(8)

(9)

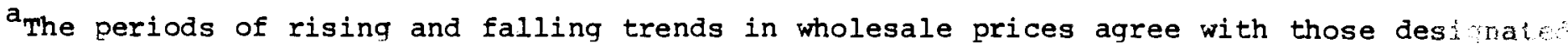
by Burns and Mitchell (1946, p. 432) for 1789-1932.

$b_{\text {WPI }}=$ Wholesale Price Index. U. S. Bureau of Labor Statistics index, 1896-1982; Warren and Pearson index, 1789-1894 (spliced to the BLS index at 1890).

$\mathrm{C}_{\mathrm{CPI}}=$ Consumer Price Index. Estimated by the BLs by splicing. several indexes together, namely: 1800-1851, Index of Prices Paid by Vermont Farmers for Family Living; 1851-1890, Consumer Price Index by Ethel D. Hoover; 1890-1912, Cost of Living Index by Albert Rees; 1913date, BLS. See Handbook of Labor statistics (1971, p. 253). We estimate the 1789 figure by splicing the warren Pearson wholesale price index to the vermont price index at 1814 (see Historical Statistics of the United States, U. S. Department of Commerce, 1975, pp. 201-202). The figure for these early years are rough approximations only.

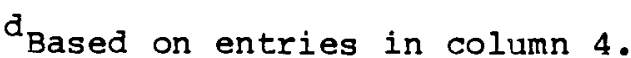

e Based on entries in column 5 .

ERates of change are computed between three-month average levels centered on business cycle peaks and troughs as dated in the NBER monthly reference chronology. 
Table 3

\section{Trends in wholesale Prices and the Relative Duration of Business Cycle Expansions and Contractions, 1790-1982}

Trend in Prices (Direction and dates) ${ }^{a}$ $\frac{\text { Business Cycle Expansions }(E)^{b}}{\text { Duration in Months }}$

Number
Business Cycle contractions $(C)^{b}$ Duration in Months

Number Average Total
Ratios (E/C)

Average Total

$(2) /(5)(3) /(6)$
(1)
(3)
(4) (5)

A. United States

Rising

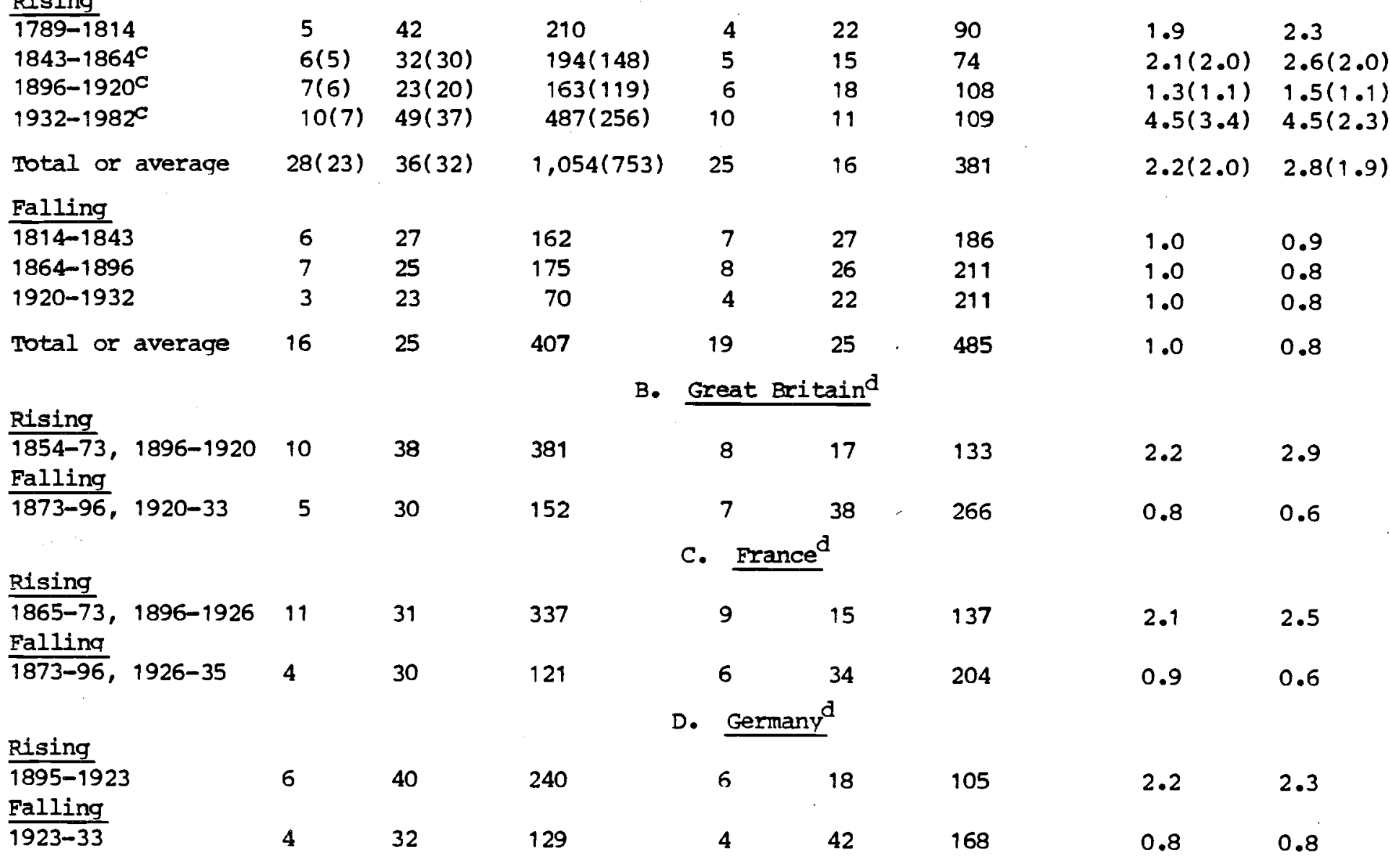

a Through 1932 based on Burns and Mitchell, 1946, p. 432. Also see Table 2 for the United States. For 1932-82, see Moore, 1983, p. 240.

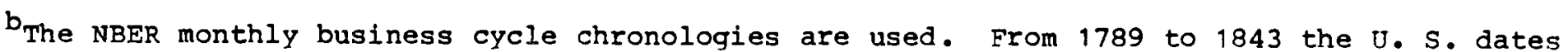
are based on Thorp (1926, p. 94) and Mitchell (1927, pp. 444-445), with years of "revival" and "prosperity" classified as as expansion, and "recession" and "depression" classified as contraction.

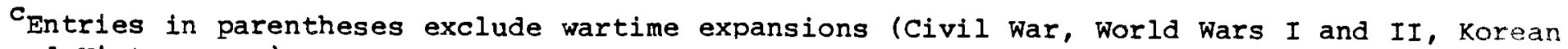
war, and Vietnam War).

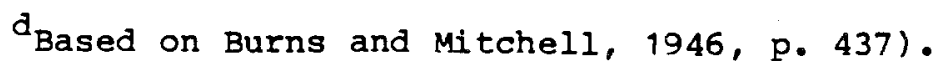


Table 4

Measures of Amplitude of Cyclical Movements in the united states, by selected subperiods, 1885-1982

\section{Number of Business Cycles (specific \\ period Cycles covered)}

Percentage Changes Associated with

$\frac{\text { Expansions }^{a}}{\text { Mean S.D. }} \quad \frac{\text { Contractions }^{b}}{\text { Mean S.D. }} \quad \frac{\text { Business Cycles }}{\text { Mean S.D. }}$
(2)
(3)
(4)
(5)
(6)

(7)

A. Industrial Activity or production ${ }^{\mathrm{d}}$

$\begin{array}{rrrrrr}+38.6 & 8.5 & -15.0 & 6.6 & 53.6 & 8.7 \\ +68.2 & 61.0 & -28.6 & 14.2 & 96.8 & 65.8 \\ +35.4 & 21.1 & -10.6 & 2.9 & 45.9 & 19.2 \\ +53.4 & 44.8 & -21.8 & 12.8 & 75.2 & 50.5 \\ +47.4 & 39.0 & -18.1 & 11.8 & 65.5 & 44.5 \\ & & & & & \\ +49.5 & 41.0 & -27.0 & 16.1 & 76.5 & 44.2 \\ +25.7 & 9.3 & -11.4 & 2.8 & 37.0 & 8.4 \\ +43.2 & 26.8 & -20.2 & 12.7 & 63.4 & 30.5 \\ +38.0 & 24.1 & -17.5 & 11.4 & 55.5 & 28.4\end{array}$

B. Factory or Nonfarm Fmployment ${ }^{f}$

$\begin{array}{lrl}1885-1912 & 8 & (8) \\ 1912-1945 & 8 & (8) \\ 1945-1982 & 8 & (8) \\ 1885-1945 & 16 & (16) \\ 1885-1982 & 24 & (24) \\ \text { Peacetime cycles }^{\text {e }} & \\ \text { 1912-1945 }_{1945-1982} & 6(6) \\ 1885-1945 & 6(6) \\ 1885-1982 & 14(14) \\ & 20(20)\end{array}$

All cycles

$\begin{array}{lr}1891-1914 & 7(6) \\ 1914-1945 & 7(7) \\ 1945-1982 & 8(8) \\ 1891-1945 & 14(13) \\ 1891-1982 & 22(21)\end{array}$

Peacetime cycles $^{e}$

$\begin{array}{rr}1914-1945 & 5(5) \\ 1945-1982 & 6(6) \\ 1891-1945 & 12(11) \\ 1891-1982 & 18(17)\end{array}$

\footnotetext{
${ }^{a}$ Means and standard deviations (S.D.) of percentage changes measured from the trough month in the series to the peak month.

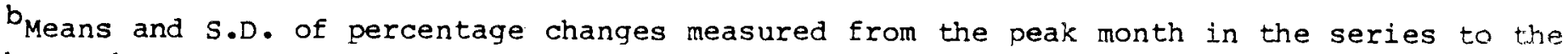
trough month.

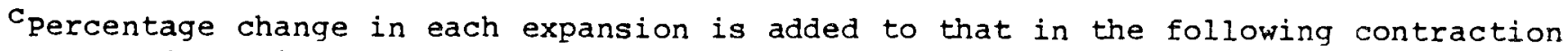
without regard to signs; the means and S.D. shown are based on the resulting measures of absolute amplitudes of trough-to-trough cycles. Entries in columns 2 and 4 add up to those in column 6 (disregarding signs), except for rounding.

d 1885-1891: Axe-Houghton index of trade and inaustrial activity; 1891-1920: Babson index of physical volume of business activity; 1920-1982: FRB index of industrial production.

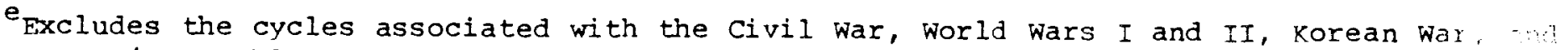
vietnam war (see Table 1, note $c$ for detail).

f 1891-1919: Factory employment index, Jerome; 1919-33: Factory employment index, BIS: 1933-82: Employment in nonagricultural establishments, BLS. SOURCE: NBER business cycle files.
} 
Table 5

Trends in Industrial Composition of Nonagricultural Employment, Selected Peak Years, 1869-1929, and Business Cycle Averages, 1929-81

\begin{tabular}{|c|c|c|c|c|c|c|c|c|c|c|}
\hline \multirow[b]{2}{*}{$\begin{array}{l}\text { Year or } \\
\text { Period }^{a}\end{array}$} & \multicolumn{4}{|c|}{ Most Cyclical Sectors } & \multicolumn{4}{|c|}{ Least Cyclical Sectors } & \multicolumn{2}{|c|}{ Totals } \\
\hline & $\begin{array}{l}\text { Mining } \\
\text { (1) }\end{array}$ & $\begin{array}{l}\text { Con- } \\
\text { tract } \\
\text { Con- } \\
\text { struc- } \\
\text { tion } \\
(2)\end{array}$ & $\begin{array}{l}\text { Manu- } \\
\text { fac- } \\
\text { tur- } \\
\text { ing } \\
(3)\end{array}$ & $\begin{array}{l}\text { Trans. } \\
\text { comm..' } \\
\text { publ.. } \\
\text { util. } \\
\text { (4) }\end{array}$ & $\begin{array}{l}\text { Whole- } \\
\text { sale } \\
\text { and } \\
\text { retail } \\
\text { trade } \\
\quad(5)\end{array}$ & $\begin{array}{l}\text { Finance } \\
\text { insur. } \\
\text { real } \\
\text { estate } \\
\quad(6)\end{array}$ & $\begin{array}{l}\text { Other } \\
\text { Service } \\
\text { Indus. } \\
(7)\end{array}$ & $\begin{array}{l}\text { Govern. } \\
\text { Fed., } \\
\text { State, } \\
\& \text { Local } \\
\text { (8) }\end{array}$ & $\begin{array}{l}\text { Most } \\
\text { Cyclical } \\
\text { Sectors } \\
\text { (9) }\end{array}$ & $\begin{array}{l}\text { Least } \\
\text { Cyclical } \\
\text { Sectors } \\
(10)\end{array}$ \\
\hline & & & & & ercent & Distribut & on & & & \\
\hline $\begin{array}{l}1869 \\
1899 \\
1929\end{array}$ & $\begin{array}{l}2.5 \\
4.0 \\
2.8\end{array}$ & $\begin{array}{l}9.5 \\
7.8 \\
6.2\end{array}$ & $\begin{array}{l}34.0 \\
31.7 \\
28.5\end{array}$ & $\begin{array}{r}9.9 \\
12.2 \\
11.0\end{array}$ & $\begin{array}{l}15.1 \\
17.1 \\
21.1\end{array}$ & $\begin{array}{l}0.8 \\
1.9 \\
4.2\end{array}$ & $\begin{array}{l}21.5 \\
18.9 \\
17.5\end{array}$ & $\begin{array}{l}6.8 \\
6.5 \\
8.6\end{array}$ & $\begin{array}{l}55.9 \\
55.7 \\
48.5\end{array}$ & $\begin{array}{l}44.2 \\
44.4 \\
51.4\end{array}$ \\
\hline $1929-37$ & 2.5 & 5.2 & 26.1 & 9.5 & 21.5 & 4.5 & 17.7 & 12.8 & 43.3 & 56.5 \\
\hline $1937-44$ & 2.1 & 4.7 & 28.7 & 7.4 & 19.2 & 3.5 & 14.6 & 19.8 & 42.9 & 57.1 \\
\hline $1944-48$ & 1.7 & 4.5 & 29.4 & 7.7 & 18.9 & 3.3 & 13.4 & 21.1 & 43.3 & 56.7 \\
\hline $1948-53$ & 1.8 & 6.3 & 29.9 & 7.7 & 20.2 & 3.8 & 14.7 & 15.5 & 45.7 & 63.3 \\
\hline $1953-57$ & 1.4 & 6.1 & 29.6 & 7.1 & 19.7 & 4.2 & 14.8 & 16.8 & 44.2 & 55.5 \\
\hline $1957-60$ & 1.3 & 6.0 & 28.2 & 6.8 & 20.1 & 4.4 & 16.2 & 16.9 & 42.3 & 57.6 \\
\hline $1960-69$ & 1.0 & 5.7 & 27.4 & 6.1 & 19.5 & 4.6 & 17.4 & 18.3 & 40.2 & 59.8 \\
\hline $1969-73$ & 0.8 & 5.0 & 25.7 & 6.0 & 20.6 & 5.0 & 15.8 & 21.0 & 37.5 & 62.4 \\
\hline $1973-79$ & 1.0 & 4.9 & 24.5 & 5.9 & 18.9 & 5.4 & 18.3 & 21.2 & 36.3 & 63.8 \\
\hline $1979-81$ & $1 \cdot 1$ & 4.7 & 22.1 & 5.6 & 22.0 & 5.6 & 19.3 & 19.7 & 33.4 & 66.6 \\
\hline
\end{tabular}

SOURCFS AND NOTES: 1869-1929: Kendrick, 1961, Table A-VII, p. 308. Persons engaged are full-time equivalent employees and proprietors and unpaid family workers. Coverage: national economy, excluding farm and agricultural services, forestry, and fisheries. Government includes armed forces. 1939-1969: U. S. Department of Commerce, Bureau of Economic Analysis, 1966 and 1973, part III, table 4, p. 76. 1969-1981: 1978 Supplement to, and more recent issues of Survey of Current Business (Dept. of Commerce). The employment estimates are based on establishment reports for the surveys of the $U$. S. Department of Labor, Bureau of Labor Statistics.

${ }^{a}$ The business cycle averages are from peak to peak, with peak years given half weight. 


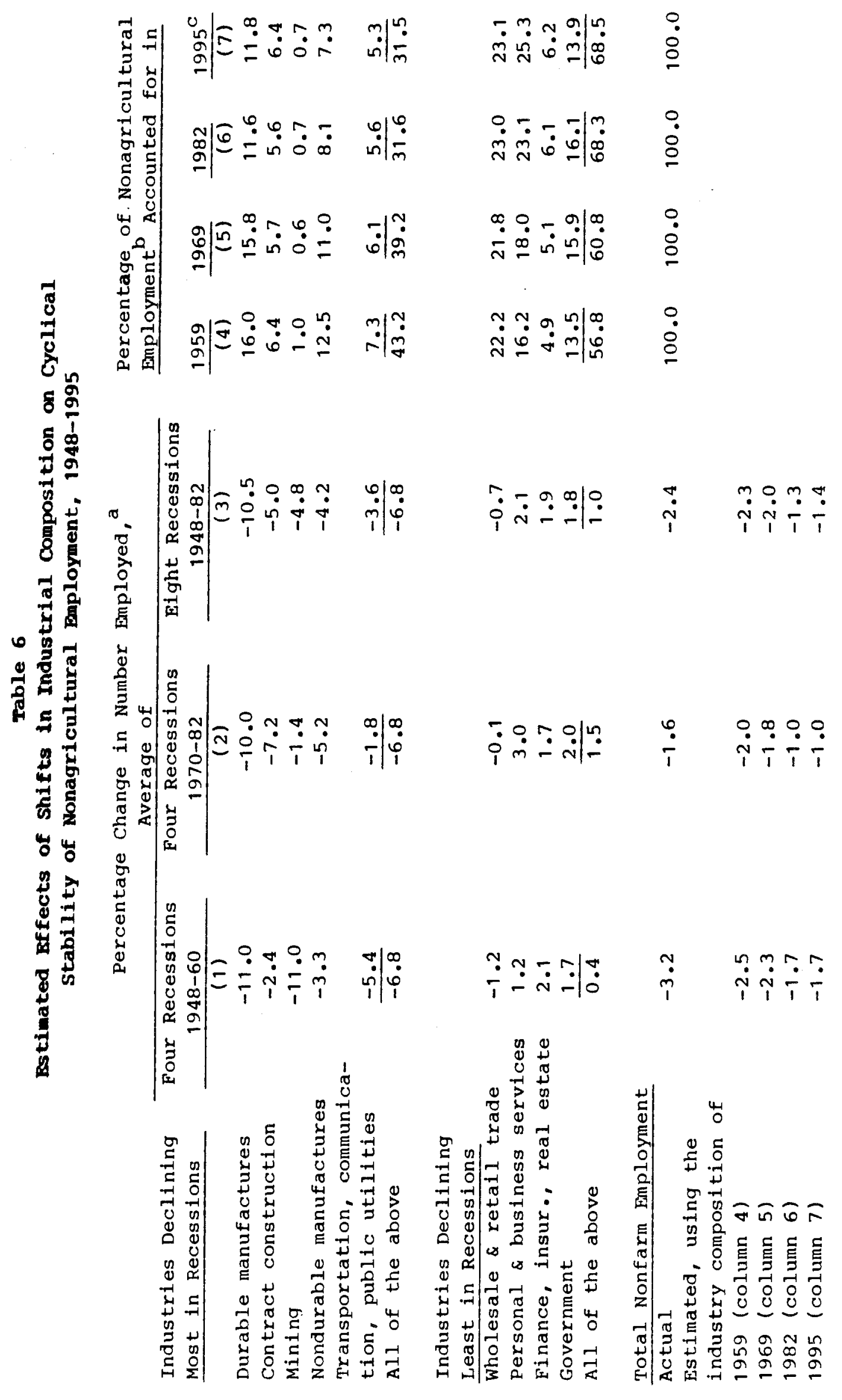


NOTES TO TABLE 6

athe percent changes in employment during recessions are computed from three month standings of seasonally adjusted data centered on business cycle peak and trough months. Simple averages are used; expressing the figures on a per year basis would not alter the results significantly. (The average durations of the recessions were: 1948-60, 10 months; 1970-82, 12 months; 1948-82, 11 months.) The measures are based on the data from the establishment survey (jobs) of the U. S. Department of Labor, Bureau of Labor Statistics.

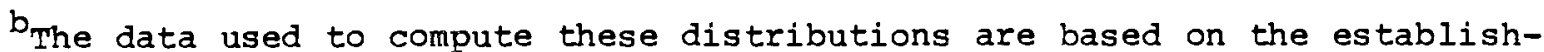
ment survey but include also self-employed and unpaid family workers (but not paid household employees). The total number of jobs represented in the distributions are (in thousands): 1959, 59,640; 1969, 76,584; 1982, 97,865; and 1995 (projected) 123,667. See Personick, 1983, Table 2, p. 26. The "moderate growth projection" for 1995 assumes average annual growth rates of employment of 1.8 percent from 1982 to 1990 and 1.5 percent from 1990 to 1995 .

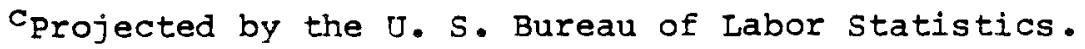




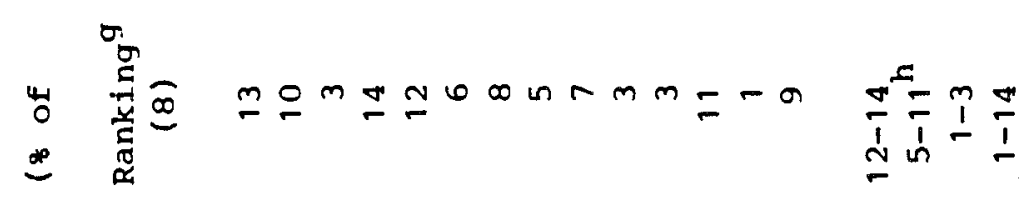

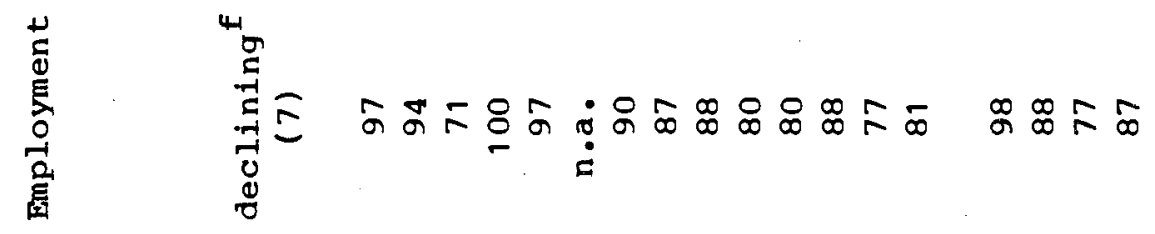

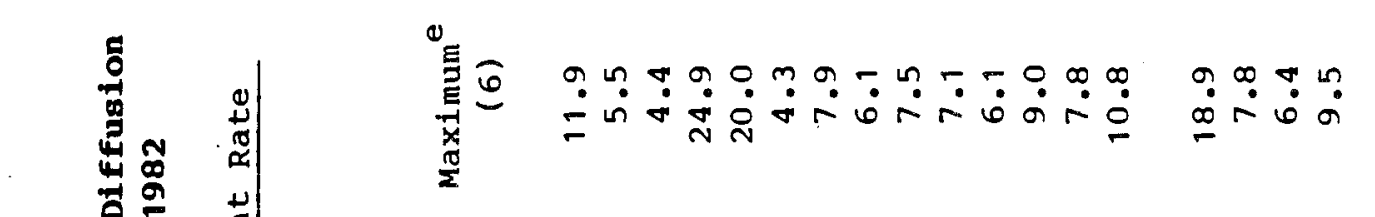

$\therefore 6$

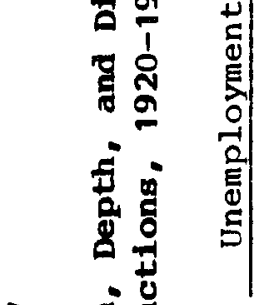

$\frac{2}{2}$

峞

ro

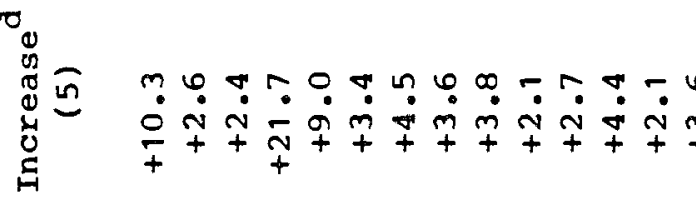

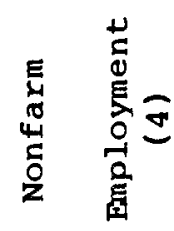

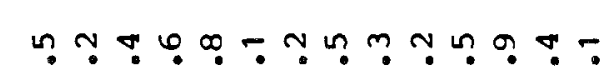

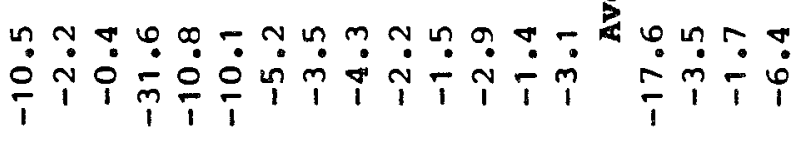

$\because \stackrel{n}{\because:}:$

๕.ำ

\begin{tabular}{|l}
0 \\
0 \\
$\vdots$ \\
0 \\
0 \\
0 \\
0 \\
0 \\
0 \\
0 \\
0 \\
0 \\
0 \\
0
\end{tabular}

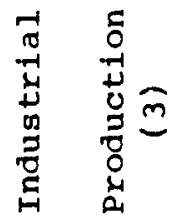

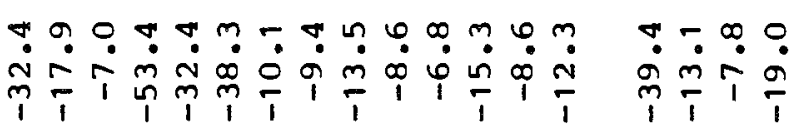

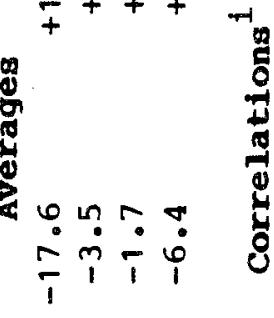

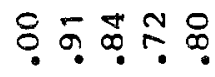

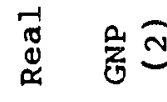

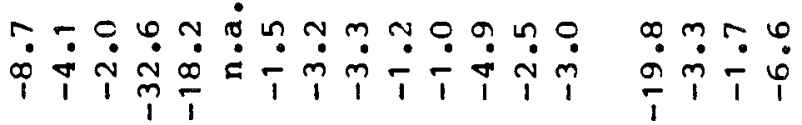

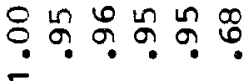

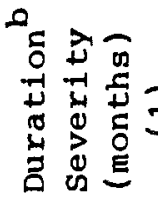

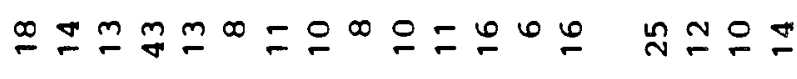

\&̊ำ

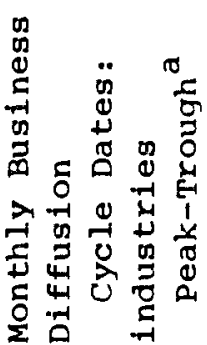

テ ฟ

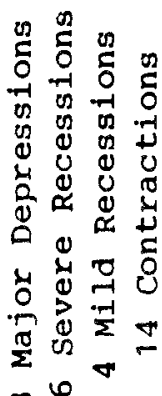
กิบ

ดे

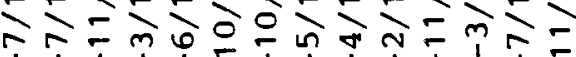

1)

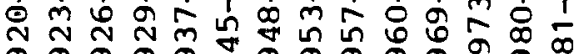

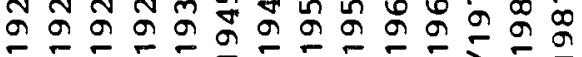

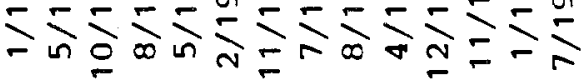

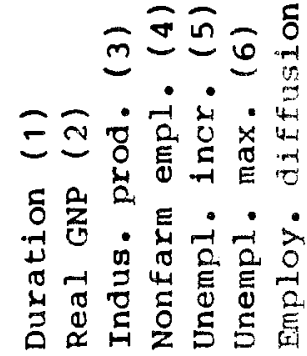




\section{NOTES TO TABLE 7}

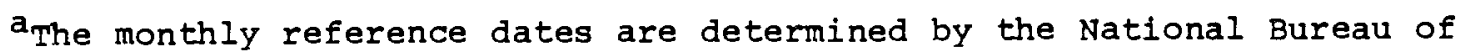
Economic Research.

${ }^{b}$ period from peak to trough according to the dates listed to the left.

CPercentage change from the peak month or quarter in the series to its trough month or quarter. Real (constant dollar) GNP is quarterly, the other series are monthly.

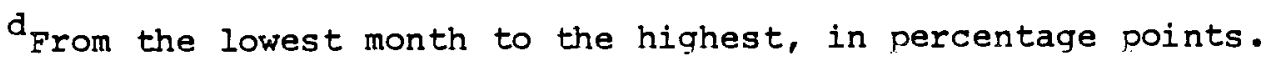

e Highest figure reached during the upswing in unemployment.

Fprior to 1948 based on cyclical changes in employment in 41 industries. Since 1948 based on changes in employment over six months, centered on the fourth month of the span: 1948-59, 30 nonagricultural industries; $1960-71,172$ industries; 1972-82, 186 industries.

${ }^{9}$ Based on averages of the ranks of entries in columns 1-7. Rank 1 denotes the mildest, rank 14 the most severe contraction.

hexcluding rank 6 , the 1945 contraction. See text. ${ }^{i}$ Correlations across columns 1-7, as indicated in the column and row headings, with signs disregarded. 
Table 8

Personal Incone Distribution by Major Type,

Selected Business Cycle Peak Years, 1913-1981

Percentage of Total Personal Income Accounted for in

Type of Income

$$
\frac{1913}{(1)} \quad \frac{1929}{(2)} \quad \frac{1937}{(3)} \quad \frac{1948}{(4)} \quad \frac{1953}{(5)} \quad \frac{1960}{(6)} \quad \frac{1969}{(7)} \quad \frac{1981}{(8)}
$$

A. Categories Declining Most in Recessions

$\begin{array}{lrrrrrrrr}\text { Wages \& salaries, private } & 48.0 & 54.9 & 53.5 & 55.8 & 58.2 & 54.2 & 52.5 & 48.0 \\ \text { Farm proprietors income } & 10.1 & 6.9 & 7.9 & 8.6 & 4.5 & 2.8 & 3.0 & 1.0 \\ \text { Nonfarm proprietors' income } & \frac{15.2}{73.3} & \frac{10.1}{71.9} & \frac{9.3}{70.7} & \frac{10.8}{75.2} & \frac{9.6}{72.3} & \frac{8.6}{65.8} & \frac{5.5}{61.0} & \frac{4.0}{53.0} \\ \text { All of the above } & & & \end{array}$

B. Categories Declining Least in Recessions

\begin{tabular}{|c|c|c|c|c|c|c|c|c|}
\hline $\begin{array}{l}\text { Wages \& salaries, government } \\
\text { Other labor income \& }\end{array}$ & 4.6 & 5.8 & 10.2 & 8.6 & 11.5 & 11.9 & 13.5 & 11.2 \\
\hline transfer payments & 0.9 & 1.7 & 3.4 & 6.4 & 6.4 & 9.7 & 12.1 & 18.9 \\
\hline Dividends & 6.0 & 7.0 & 6.6 & 3.5 & 3.3 & 3.1 & 2.9 & 2.5 \\
\hline Interest & 4.0 & 6.4 & 5.0 & 2.5 & 2.7 & 6.1 & 7.8 & 13.1 \\
\hline Net rent & 11.2 & 7.0 & 4.3 & 3.7 & 3.8 & 3.5 & 2.5 & 1.3 \\
\hline All of the above & $\overline{26.7}$ & $2 \overline{7.9}$ & $\overline{29.5}$ & $2 \overline{24.7}$ & 27.7 & $\overline{34.3}$ & $\overline{38.8}$ & 47.0 \\
\hline
\end{tabular}

SOURCE: 1913-1953, and Creamer (1956, pp. xxix, 9 and 116-123). 1960-1981, computed by Cullity (1983, Tables 1 and 2) from personal income statistics of the U. S. Department of Commerce, Bureau of Economic Analysis. See also Table 9 below. 
Table 9

Bstimated Effects of Shifts in Types of Income on Cyclical

Stability of Total Personal Income, 1937-1982

Percentage Change During Business Cycle Contractions

Categories Declining

Most in Recessions

Wages \& salaries, private

Farm proprietors' income

Nonfarm proprietors' income

All of the above

Current Dollar Incomes

$\frac{1937-1938}{(1)}$

(1)

$-10.2$

$-21.4$

$\frac{-4 \cdot 5}{-10.7}$

$+11.0$

$+9.0$

$+2 \cdot 1$

$+1.8$

other labor income \&

Interest

Constant-Dollar Incomes
Aver. 7

recessions

$1948-1980$

(3)

$-3.4$

$-13 \cdot 0$

$\frac{-4.7}{-4.1}$

$1981-1982$

(4)

$-3.9$

$-22.1$

$\frac{-1 \cdot 8}{-4 \cdot 1}$ transfer payments

Dividends

Net rent

All of the above

$+20.8$

$-31.9$

$-2.8$

$\frac{+6.5}{-0.5}$

$+10.5$

$+4.2$

$+9.8$

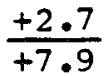

$-7.7$

Actual

Estimated using,

1913 weights (Table. 8, col. 1) -8.3

1937 weights (Table 8, col. 3) -7.7

1948 weights (Table 8, col. 4) -6.7

1960 weights (Table 8, col. 6) -4.1

1981 weights (Table 8, col. 8) -1.2

Total Personal Income

(1)

NOTE: Percentage changes in 1937-38 and 1948-49 based on Creamer, 1956, p. xxix; in 194880 and 1981-82 based on Cullity, 1983, Table 2. Also see text and Table 8 . 
Table 10

\section{Average Growth Rates and Variability of Economic Change, Selected Periods, 1903-1981}

$\begin{array}{ll} & \text { No. of } \\ \text { Years } & \text { Period }^{a} \quad \text { Covered }\end{array}$

(1)

(2)

10

1903-13

1923-29

$1948-69$

Total

\begin{abstract}
No. of Business Cycles Covered ${ }^{\mathrm{C}}$
\end{abstract}

(3)

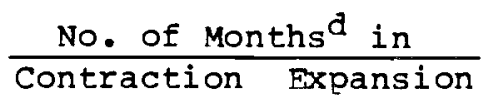

(4)
Percent of Time in Contractione

(6)
Growth in Real GNP ( $z$ Average $^{f}$ St. Dev. $q$

Periods of Relatively High Growth

$\begin{array}{rrrrr}60 & 64 & 48.4 & 3.4 & 6.1 \\ 27 & 48 & 36.0 & 3.5 & 3.8 \\ 39 & 214 & 15.4 & 3.9 & 2.6 \\ 126 & 326 & 27.9 & 3.7 & 3.7\end{array}$

Periods of Relatively Low Growth

\begin{tabular}{|c|c|c|c|c|c|c|c|}
\hline $1913-23^{\prime}$ & 10 & 3 & 48 & 76 & 38.7 & 2.4 & 8.6 \\
\hline $1929-48$ & 19 & 3 & 64 & 167 & 27.7 & 2.5 & 0.4 \\
\hline $1969-81$ & 12 & 3 & 33 & 106 & 23.7 & 2.8 & 2.9 \\
\hline Total & 41 & 9 & 145 & 349 & 29.4 & 2.6 & .2 \\
\hline
\end{tabular}

For each period listed, the initial and terminal dates are business cycle peak years according to the annual reference chronology of the National Bureau.

$\mathrm{b}_{\text {Number }}$ of complete years covered.

CNumber of complete peak-to-peak cycles from the initial to the terminal year.

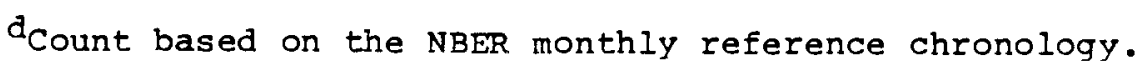

Entries in column 4 are divided by the sums of entries in columns 4 and 5 and multiplied by 100 .

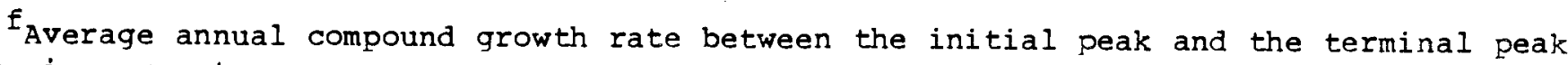
years, in percent.

Gstandard deviation of the annual growth rates for all years in the given period (as identified in columns 1-2).

SOURCE: John W. Kendrick, 1961 (GNP in 1958 dollars, 1903-08); U. S. Department of Commerce, Bureau of Economic Analysis (GNP in 1958 dollars and in 1972 dollars, 190981). Most of the historical data and measures are taken from the U. S. Department of Commerce, Bureau of Economic Analysis, 1973. 


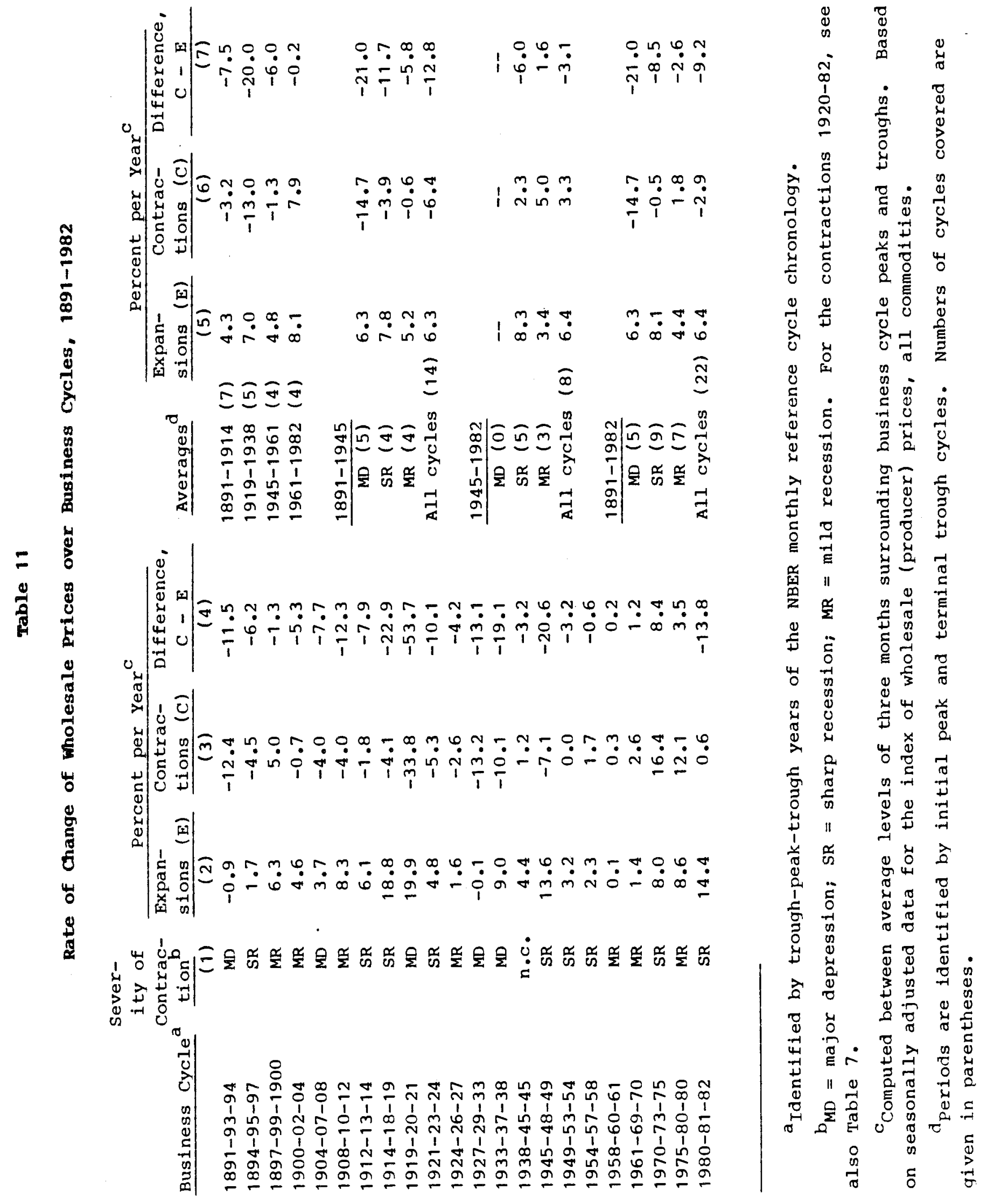


Table 12

Timing of Turning points in Treasury Bill Rates and Corporate Bond Yields During Business Cycles, 1919-1982

Business Cycle

Trough

(1)

Mar. 1919
JuIy 1921
July 1924
Nov. 1927
Mar. 1933
June 1938
Oct. 1945
Oct. 1949
Aug. 1954
Apr. 1958
Feb. 1961
Nov. 1970
Mar. 1975
July 1980
Nov. 1982

Mar. 1919

JuIy 1921

July 1924

Nov. 1927

Mar. 1933

June 1938

oct. 1945

Oct. 1949

Aug . 1954

Apr . 1958

Mar. 1975

Nov. 1982
Feb. 1961

Leads (-) or Iags $(t)$, in Months

\begin{tabular}{|c|c|c|c|c|c|}
\hline Treasury & Bill Ratea & Corporate & Bond Yield & Bond Yield & vs. Bill Rate $^{C}$ \\
\hline Trough & Peak & Trough & Peak & Trough & Peak \\
\hline
\end{tabular}

(4)

(5)

(6)

(7)

(8)

Jan. 1920

May $1923+13$

Oct. $1926+1$

Aug. $1929 \quad-2$

May $1937+35$

Feb. $1945+31$

Nov. 1948

July 1953

July 1957

May 1960

Nov. 1969

Nov. 1973

Jan. 1980

July 1981

$\begin{array}{ll}+5 & -1 \\ -2 & +14\end{array}$

$+5$

$-1 \quad+1$

$-11$

$-3+5$

$-1 .+46$

$+30$

$+1$

$+1$

$-35$

$+11$

$-9$

$+6$

$-1+8$

$-1+1$

$-5+2$

$+2+25$

$+9+25$

$+2+30$

$\begin{array}{ll}-7 & -1\end{array}$

$+6$

$-1$

$+1$

$-4$

$+7$

$+13$

$+2$

$+2$

$+7$

0

$+4$

0

$-1$

0

$+2$

$+1$

$+5$

$+4$

0

$+9$

\section{Averages}

Pre-1945

$$
1919-1929
$$

1919-1945

$\begin{array}{r}+4 \\ +16\end{array}-3 \quad+6$

$-2+19$

$+2$

$-6$

$+4$

$+2$

$+1$

Post -1945

$1945-1960$

$1961-1982$

$\begin{array}{rrr}0 & -2 & +4 \\ +6 & +2 & +17\end{array}$

$-3$

$+2$

$+6+10$

$+1$

$+4$

$\begin{array}{lll}+9 & -1 & +14 \\ +4 & -1 & +10\end{array}$

$-2$

$+7$

$+3$

All observations
Onitting $1933-45^{d}$

$+7$

$+2$ 


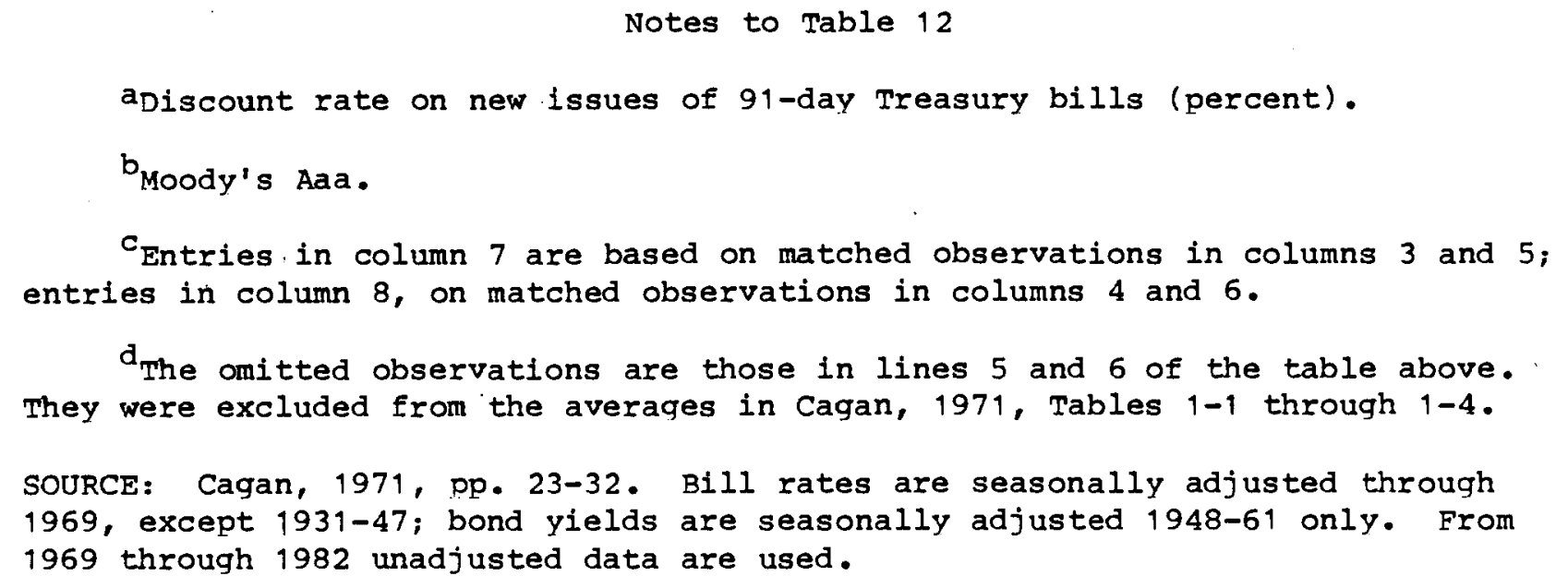




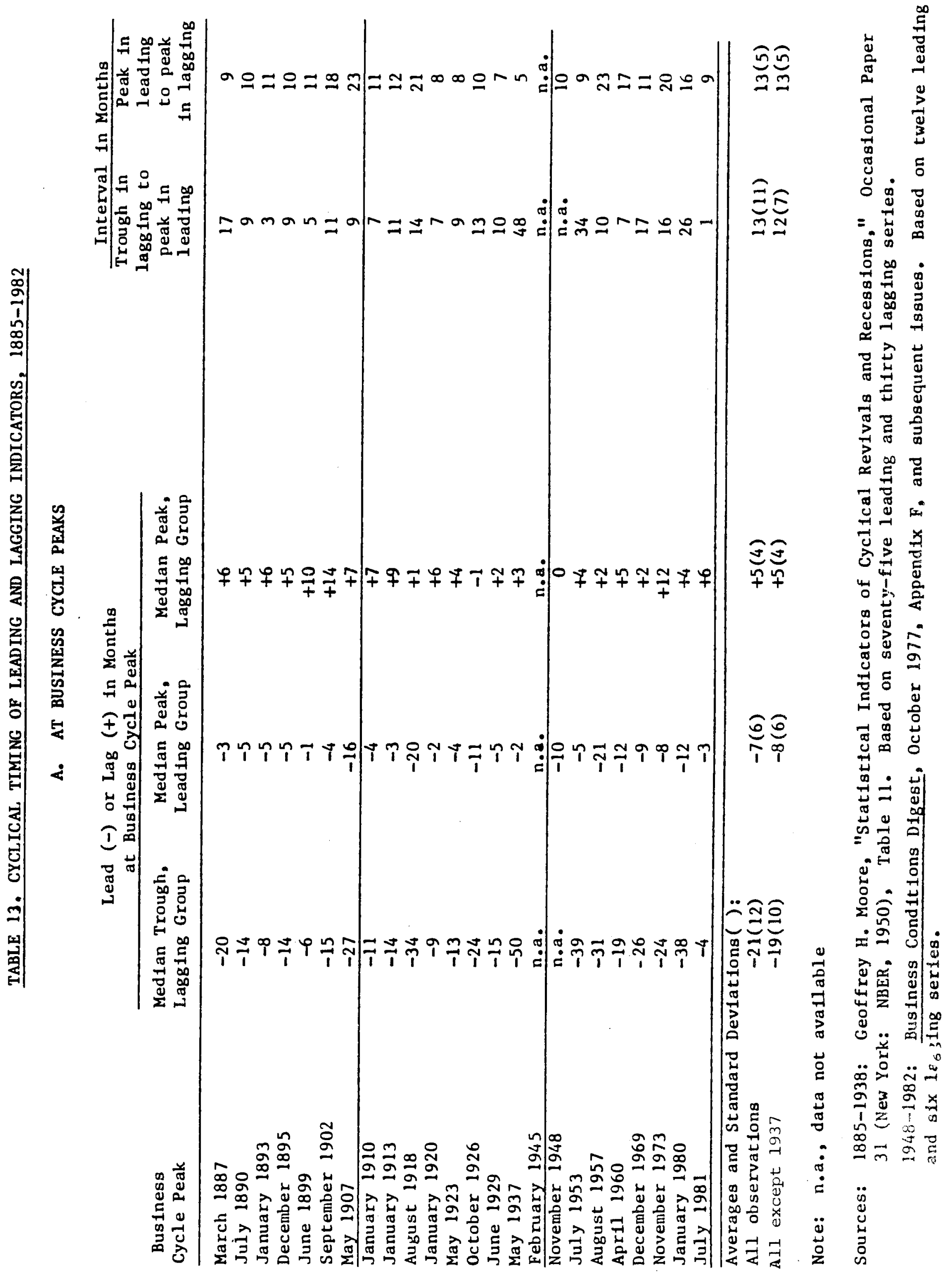




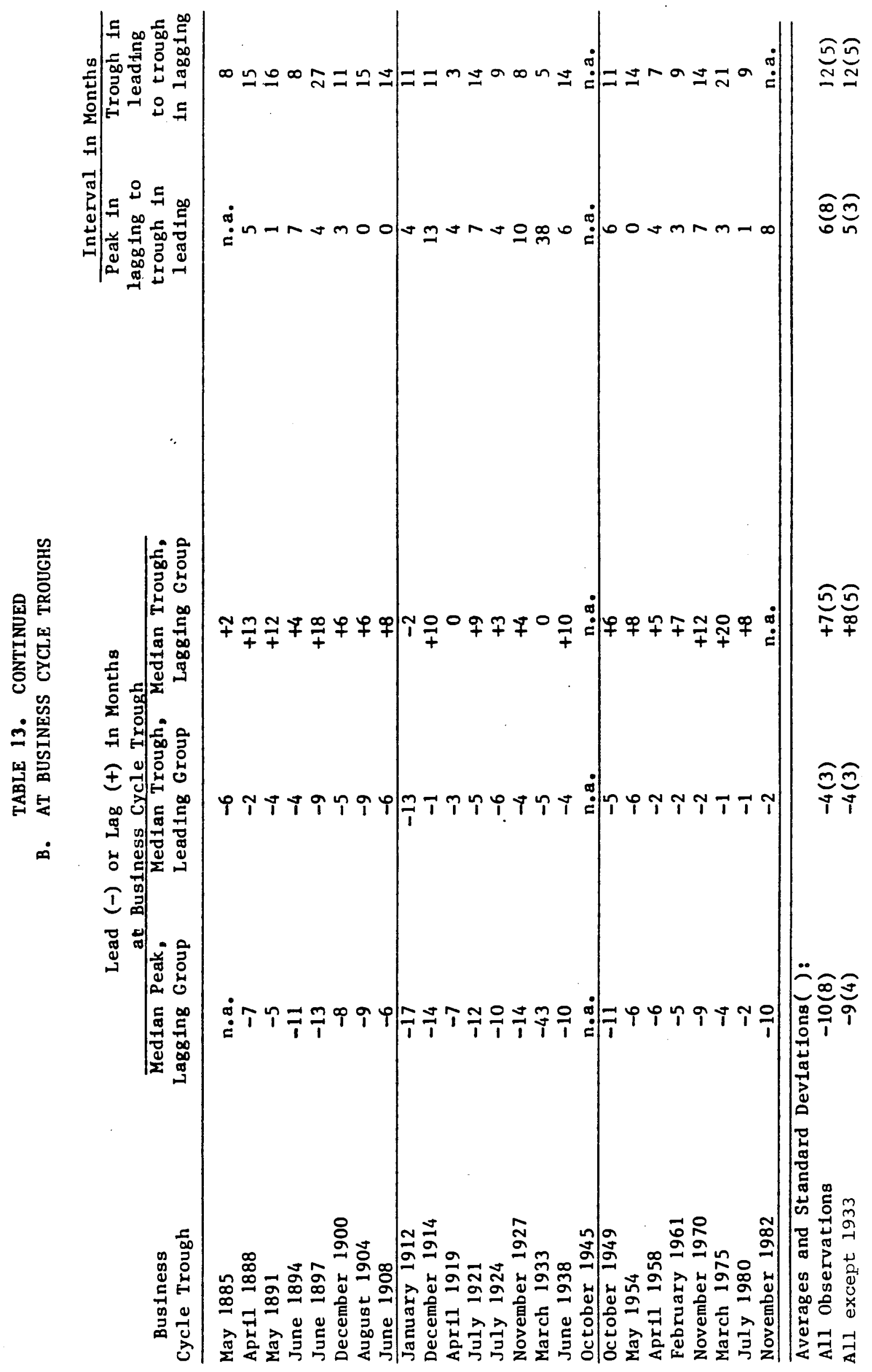


Chart 1. Wholesale Prices, All Commodities, Average

Reference Patterns, 1854-1982

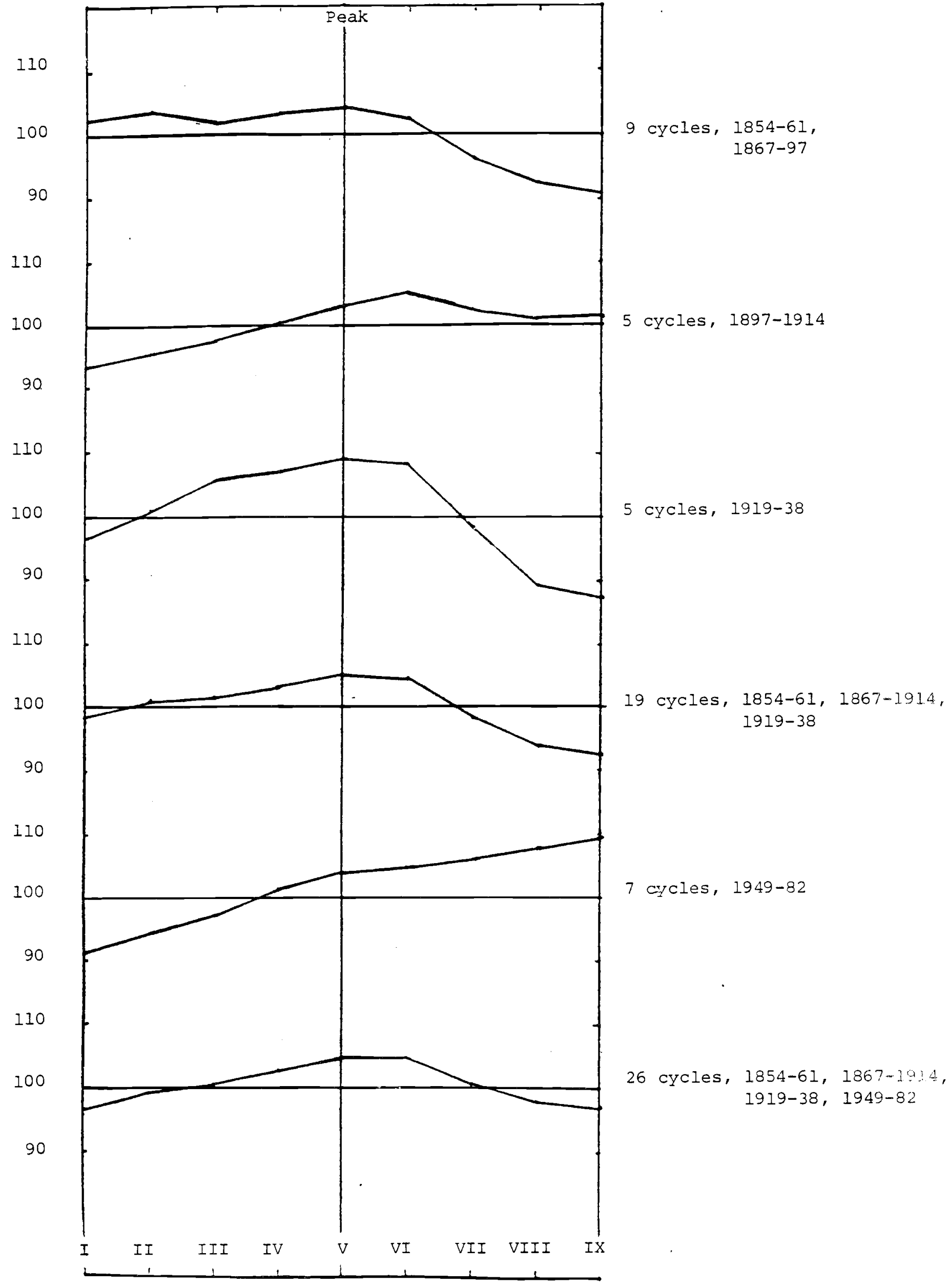


Chart 2. Short-Term Interest Rates, Average Reference Patterns, 1858-1982

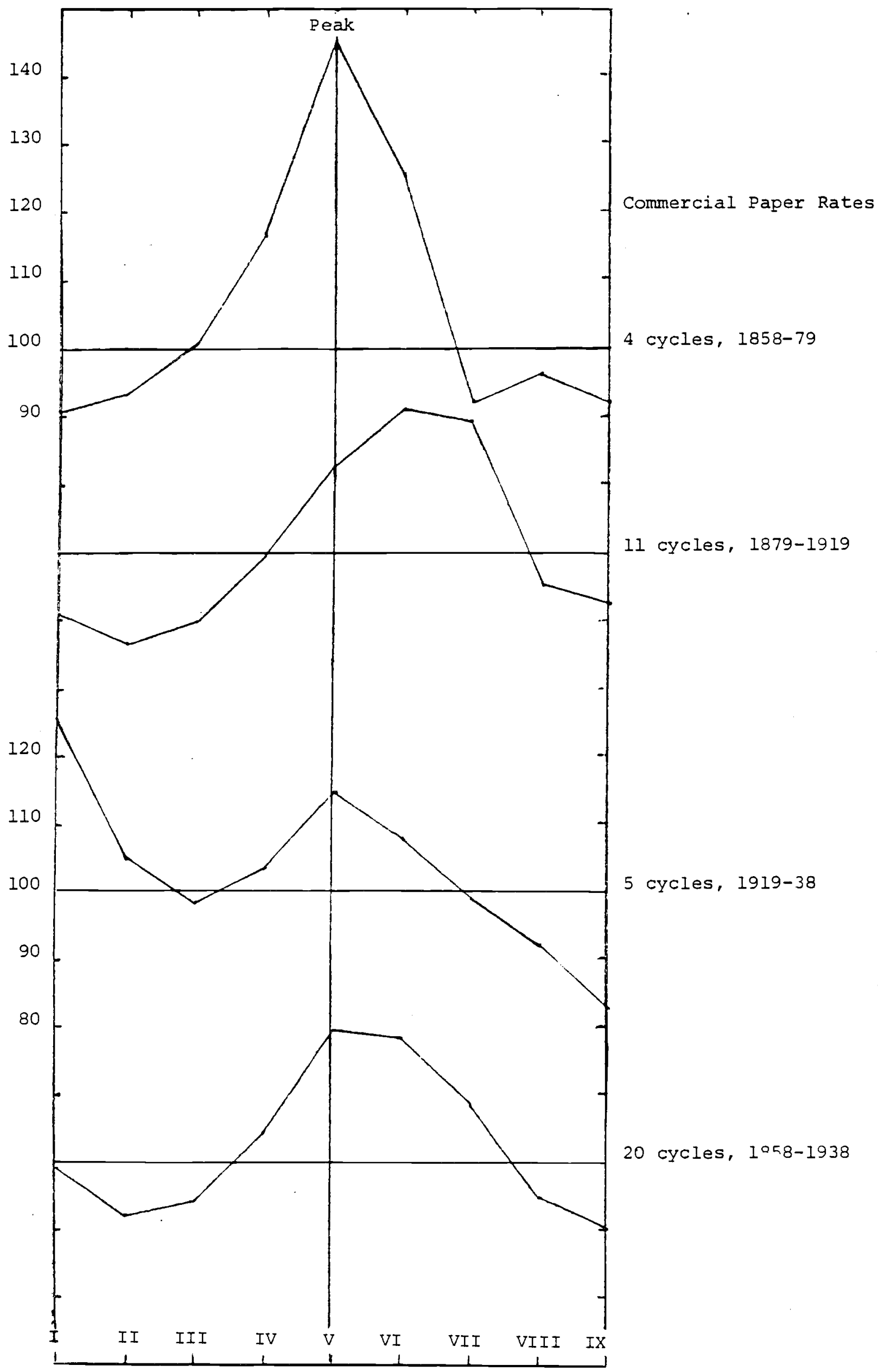




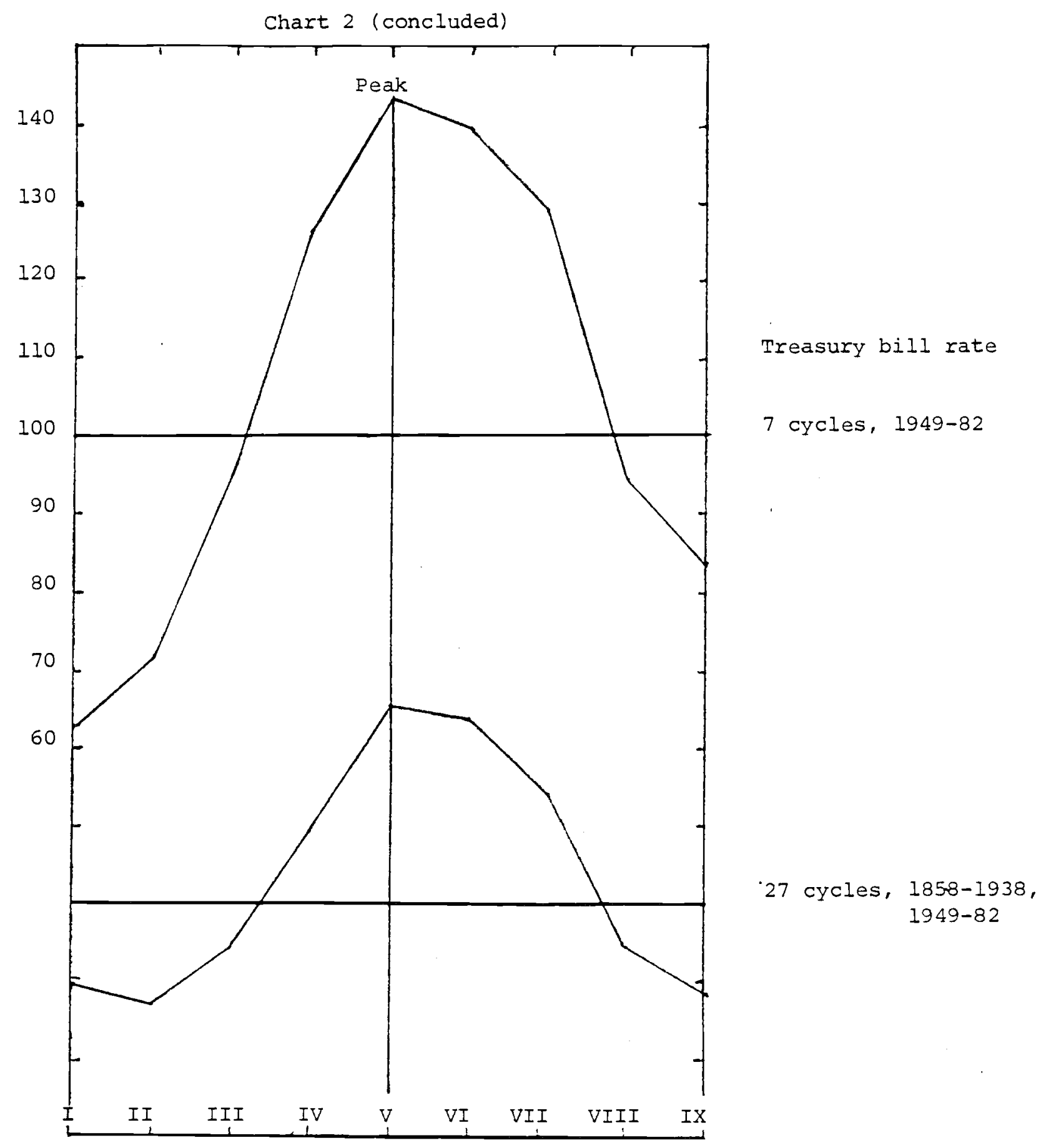


Chart 3. Long-Term Interest Rates, Average Reference Patterns, 1858-1982

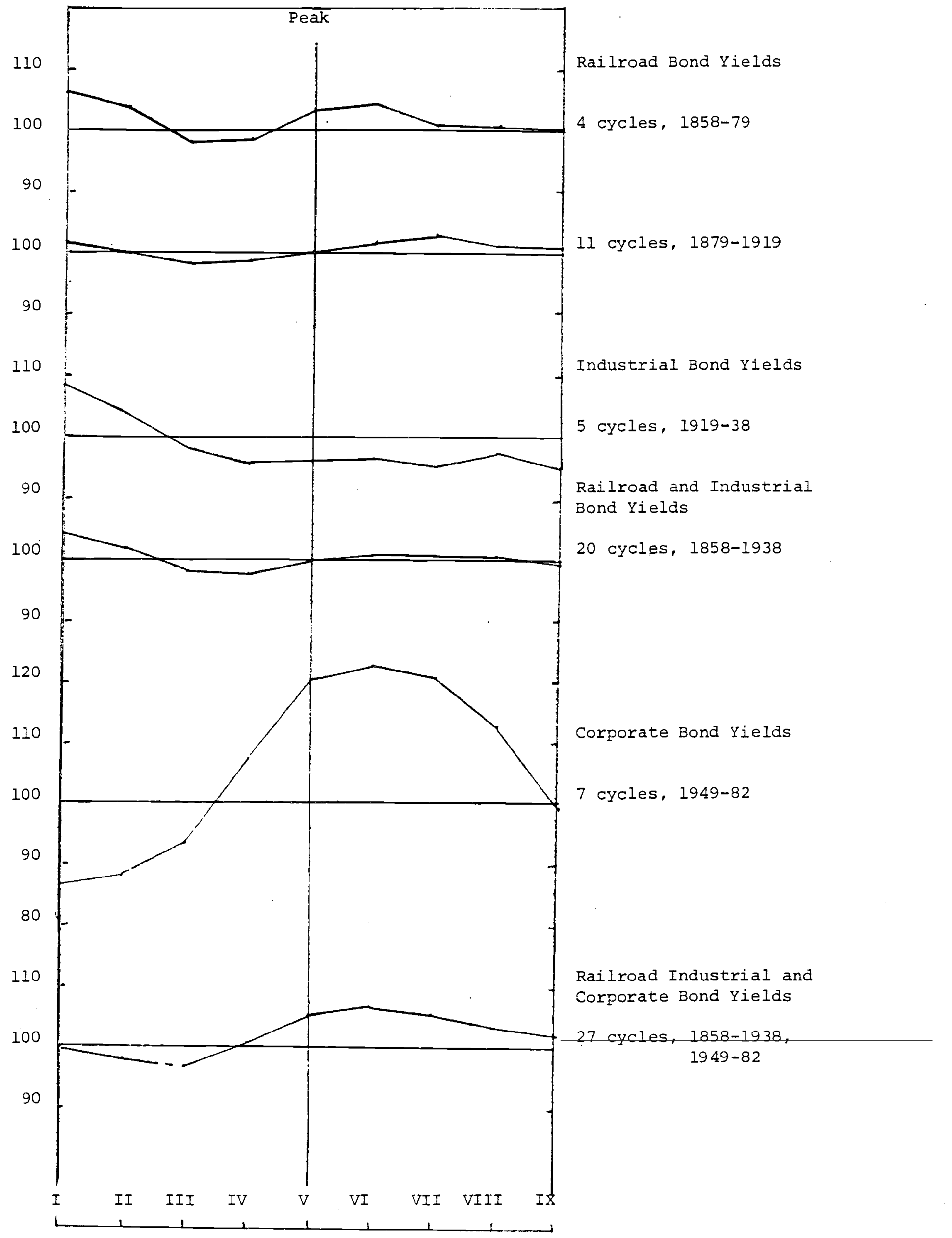

